\title{
Applications of CYP450 Testing in the Clinical Setting
}

\author{
C. F. Samer · K. Ing Lorenzini · V. Rollason • \\ Y. Daali · J. A. Desmeules
}

Published online: 16 April 2013

(C) The Author(s) 2013. This article is published with open access at Springerlink.com

\begin{abstract}
Interindividual variability in drug response is a major clinical problem. Polymedication and genetic polymorphisms modulating drug-metabolising enzyme activities (cytochromes P450, CYP) are identified sources of variability in drug responses. We present here the relevant data on the clinical impact of the major CYP polymorphisms (CYP2D6, CYP2C19 and CYP2C9) on drug therapy where genotyping and phenotyping may be considered, and the guidelines developed when available. CYP2D6 is responsible for the oxidative metabolism of up to $25 \%$ of commonly prescribed drugs such as antidepressants, antipsychotics, opioids, antiarrythmics and tamoxifen. The ultrarapid metaboliser (UM) phenotype is recognised as a cause of therapeutic inefficacy of antidepressant, whereas an increased risk of toxicity has been reported in poor metabolisers (PMs) with several psychotropics (desipramine, venlafaxine, amitriptyline, haloperidol). CYP2D6 polymorphism influences the analgesic response to prodrug opioids (codeine, tramadol and oxycodone). In PMs for CYP2D6, reduced analgesic effects have been observed, whereas in UMs cases of life-threatening toxicity have been reported with tramadol and codeine. CYP2D6 PM phenotype has been associated with an increased risk of toxicity of metoprolol, timolol, carvedilol and propafenone.
\end{abstract}

C. F. Samer $(\varangle)$ · K. I. Lorenzini · V. Rollason · Y. Daali ·

J. A. Desmeules

Clinical Pharmacology and Toxicology, Geneva University

Hospitals, Rue Gabrielle-Perret-Gentil 4,

1211 Geneva, Switzerland

e-mail: Caroline.Samer@hcuge.ch

C. F. Samer · Y. Daali · J. A. Desmeules

Swiss Centre for Applied Human Toxicology,

Geneva University, Geneva, Switzerland
Although conflicting results have been reported regarding the association between CYP2D6 genotype and tamoxifen effects, CYP2D6 genotyping may be useful in selecting adjuvant hormonal therapy in postmenopausal women. CYP2C19 is responsible for metabolising clopidogrel, proton pump inhibitors (PPIs) and some antidepressants. Carriers of CYP2C19 variant alleles exhibit a reduced capacity to produce the active metabolite of clopidogrel, and are at increased risk of adverse cardiovascular events. For PPIs, it has been shown that the mean intragastric $\mathrm{pH}$ values and the Helicobacter pylori eradication rates were higher in carriers of CYP2C19 variant alleles. CYP2C19 is involved in the metabolism of several antidepressants. As a result of an increased risk of adverse effects in CYP2C19 $\mathrm{PMs}$, dose reductions are recommended for some agents (imipramine, sertraline). CYP2C9 is responsible for metabolising vitamin $\mathrm{K}$ antagonists (VKAs), non-steroidal antiinflammatory drugs (NSAIDs), sulfonylureas, angiotensin II receptor antagonists and phenytoin. For VKAs, CYP2C9 polymorphism has been associated with lower doses, longer time to reach treatment stability and higher frequencies of supratherapeutic international normalised ratios (INRs). Prescribing algorithms are available in order to adapt dosing to genotype. Although the existing data are controversial, some studies have suggested an increased risk of NSAID-associated gastrointestinal bleeding in carriers of CYP2C9 variant alleles. A relationship between CYP2C9 polymorphisms and the pharmacokinetics of sulfonylureas and angiotensin II receptor antagonists has also been observed. The clinical impact in terms of hypoglycaemia and blood pressure was, however, modest. Finally, homozygous and heterozygous carriers of CYP2C9 variant alleles require lower doses of phenytoin to reach therapeutic plasma concentrations, and are at increased risk of toxicity. New diagnostic techniques made safer and 
easier should allow quicker diagnosis of metabolic variations. Genotyping and phenotyping may therefore be considered where dosing guidelines according to $C Y P$ genotype have been published, and help identify the right molecule for the right patient.

\section{Introduction}

Interindividual variability in drug response is a major problem in clinical practice. Factors known to influence drug responses are indeed either intrinsic (age, gender, race/ethnicity, disease states, organ dysfunctions) or extrinsic/environmental (smoking, diet, concomitant medications) [1]. Genetics is another source of interindividual variability known to influence drug response. Indeed, considering that 60 to $80 \%$ of commercialised drugs are metabolised by polymorphic enzymes, adverse drug reactions (ADRs) as well as therapeutic failure may be attributed to genetic variations in drug-metabolising enzymes.

A US meta-analysis estimated that the incidence of serious side effects is $6.7 \%$ and 100,000 deaths are yearly due to ADRs [2]. The associated costs are considerable (US $\$ 100$ billion). Up to $7 \%$ of hospitalisations are due to ADRs in the UK and $13 \%$ in Sweden [3, 4]. Conversely, it was reported that $25-60 \%$ of common drug therapies were successful [5]. Polymedication is another well-established source of variability in drug response in the elderly population [1]. The cytochromes P450 (CYP) involved in the metabolism of various substrates are presented in Table 1, and drug-inhibiting or drug-inducing CYP are listed in Table 2. Drug interactions may indeed mimic genetic defects (such as with CYP inhibitors) or increased metabolism (CYP inducers).

In order to assess the clinical importance, a number of factors need to be taken into account. The clinical impact of a given polymorphism will depend on whether the pathway is major, whether it leads to an active metabolite and its relative potency compared to the parent drug, on the therapeutic window of the drug and on the presence of other pathways of elimination. Phenotyping and/or genotyping should allow the identification of patients at risk of inefficacy or toxicity and offer tools to individualise drug prescription.

We performed a review by means of a structured computerised search in the Medline database (1966-2012). Keywords were pharmacogenetics, polymorphism, drug interactions, cytochrome P450 (CYP), CYP2D6, CYP2C9, CYP2C19, phenotyping, genotyping, and the relevant drugs and therapeutic classes discussed hereafter. Articles in English and French were selected. References in relevant articles were also retrieved.

\section{Clinical Impact of CYP450 Polymorphisms on Drug Therapy}

The cytochromes P450 (CYP) are a group of isoenzymes located primarily in the endoplasmic reticulum of hepatic cells. They catalyse oxidative or reductive reactions of endogenous lipophilic (steroids, bile acids, fatty acids, prostaglandins) and exogenous compounds (drugs) into more polar (hydrophilic) products, allowing their elimination in the urine. The human genome comprises 57 CYP genes which are classified according to sequence homology into 18 families and 44 subfamilies [6]. The CYP 1 to 3 families are involved in phase I drug metabolism, whereas CYP 4 to 51 are associated with endobiotic metabolism.

\subsection{Cytochrome P450 2D6 and Clinical Impact}

Even though CYP2D6 only represents $1-5 \%$ of the CYP liver content, it is responsible for the oxidative metabolism of up to $25 \%$ of commonly prescribed drugs such as antidepressants, antipsychotics, opioids, antiarrythmics and tamoxifen, many of which have a narrow therapeutic window [7-9]. CYP2D6 is encoded by a highly polymorphic gene, with more than 70 alleles and 130 genetic variations described [10]. Marked interethnic variation in the frequency of the various alleles has been reported $[9,11,12]$ and are available in various online databases (dbSNP [13], ALFRED [14], 1000 Genomes [15]). Individuals can be distinguished into four phenotypic groups which are predicted by the number of functional alleles. Poor metabolisers (PMs) carry two null alleles responsible for an absent enzymatic activity. They represent 5-10 \% of the Caucasian population, whereas this phenotype is rare in Asians and highly variable in those of African ancestry $[12,16]$. In Europe, $95-99 \%$ of PMs are detected by screening the main null alleles $* 3, * 4, * 6$ and the gene deletion *5 [17]. The null allele CYP2D $6 * 4$ (splice defect) is present in $12-21 \%$ of the Caucasians but only in 1-2\% of Asians and Africans. Intermediate metabolisers (IMs) carry a combination of either a null allele or two deficient alleles. The common deficient alleles are CYP2D6*9, *10,*17 and $* 41$ [16]. IMs represent $10-15 \%$ of Caucasians but are much more frequent in Asians (up to $50 \%$ ) because of the high prevalence of the defective allele $* 10$, and up to $30 \%$ of Africans in whom the allele $* 17$ is frequent. The carriers of gene duplications or multi-duplications are assigned to the ultrarapid metaboliser (UMs) phenotype (1-10\% of Caucasians) [18]. UMs are more prevalent in the Southern European countries (Spain 7-10\%, Sicily $10 \%$ vs Sweden 1-2 \%). Gene duplications are described in $20 \%$ of Saudi Arabians and $29 \%$ of Ethiopians. The extensive metabolisers (EMs) have normal enzymatic activity and represent $60-85 \%$ of the Caucasian population. 
Table 1 Substrates of cytochromes P450 (CYP). Substrates are classified in alphabetical order according to their International Nonproprietary

Name (non-exhaustive list). A dark green square indicates a major metabolic pathway and a light green square a minor metabolic pathway

DRUGS INTERACTIONS AND CYTOCHROMES P450

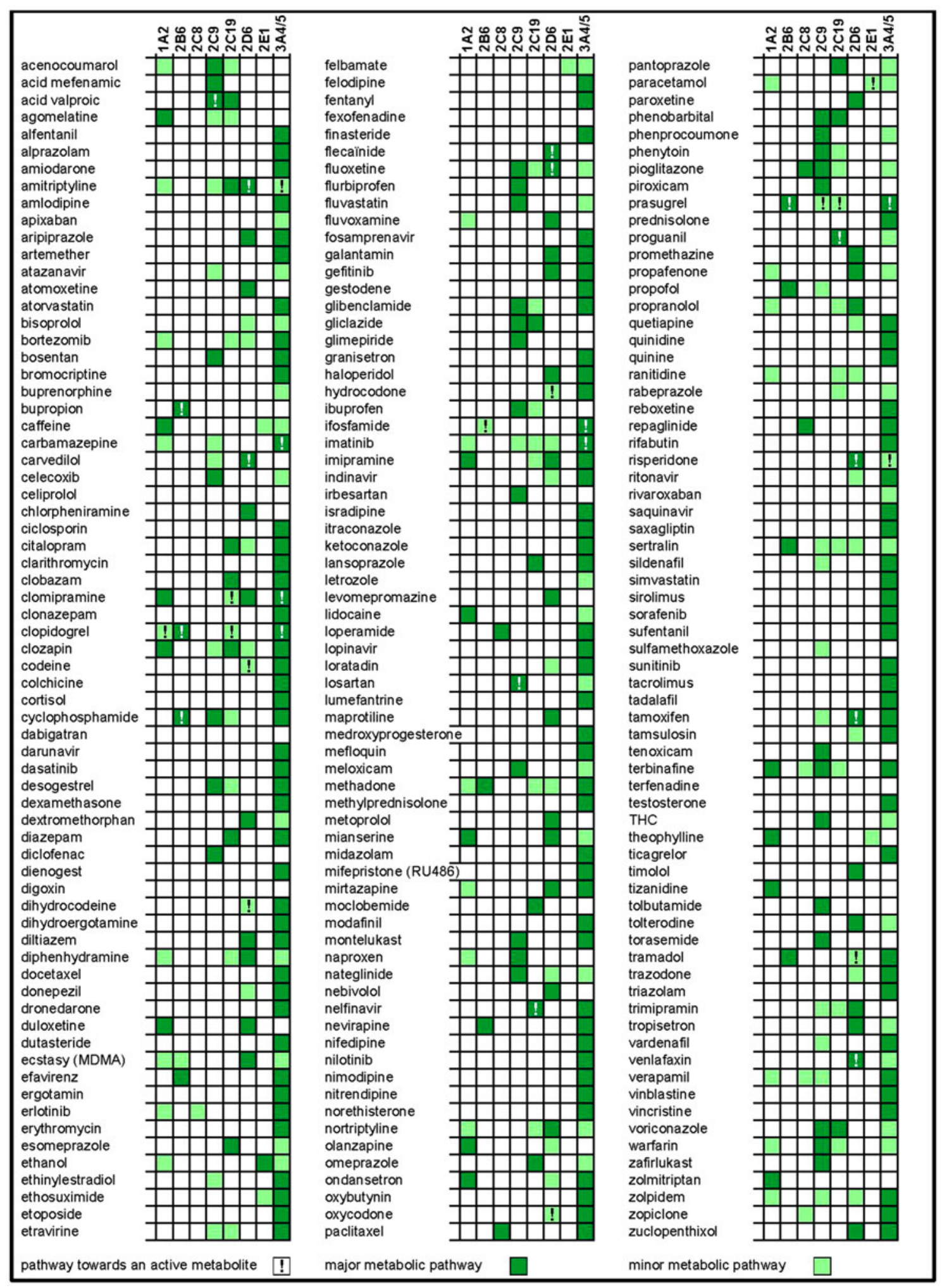


Table 2 Inhibitors and Inducers of cytochromes P450 (CYP). Inhibitors and inducers are classified in alphabetical order according to their International Nonproprietary Name. Inhibition/induction strength is indicated by a dark green square (potent) or light green square (weak). The impact of the interaction will depend on the importance of the metabolic pathway for the substrate

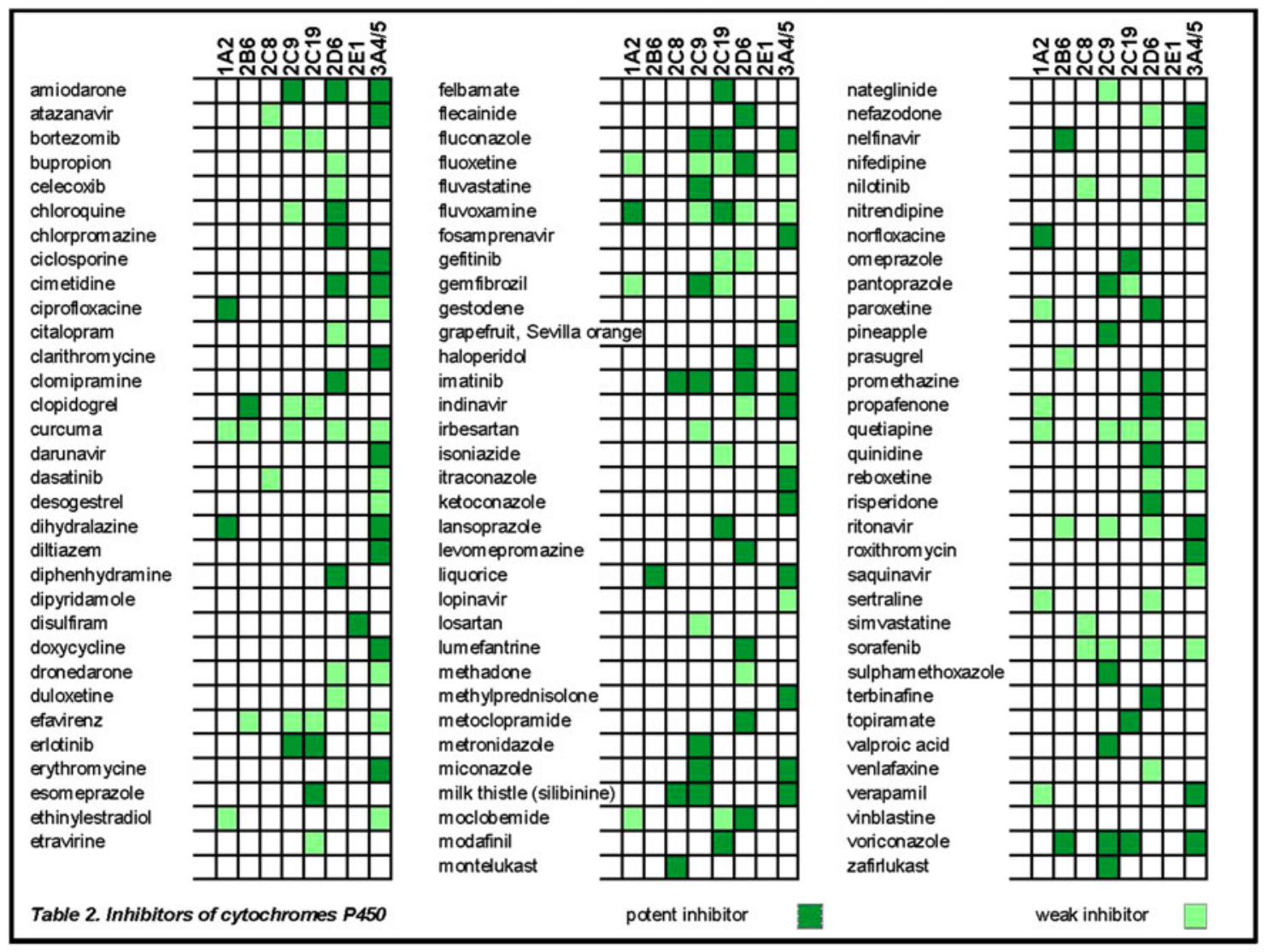

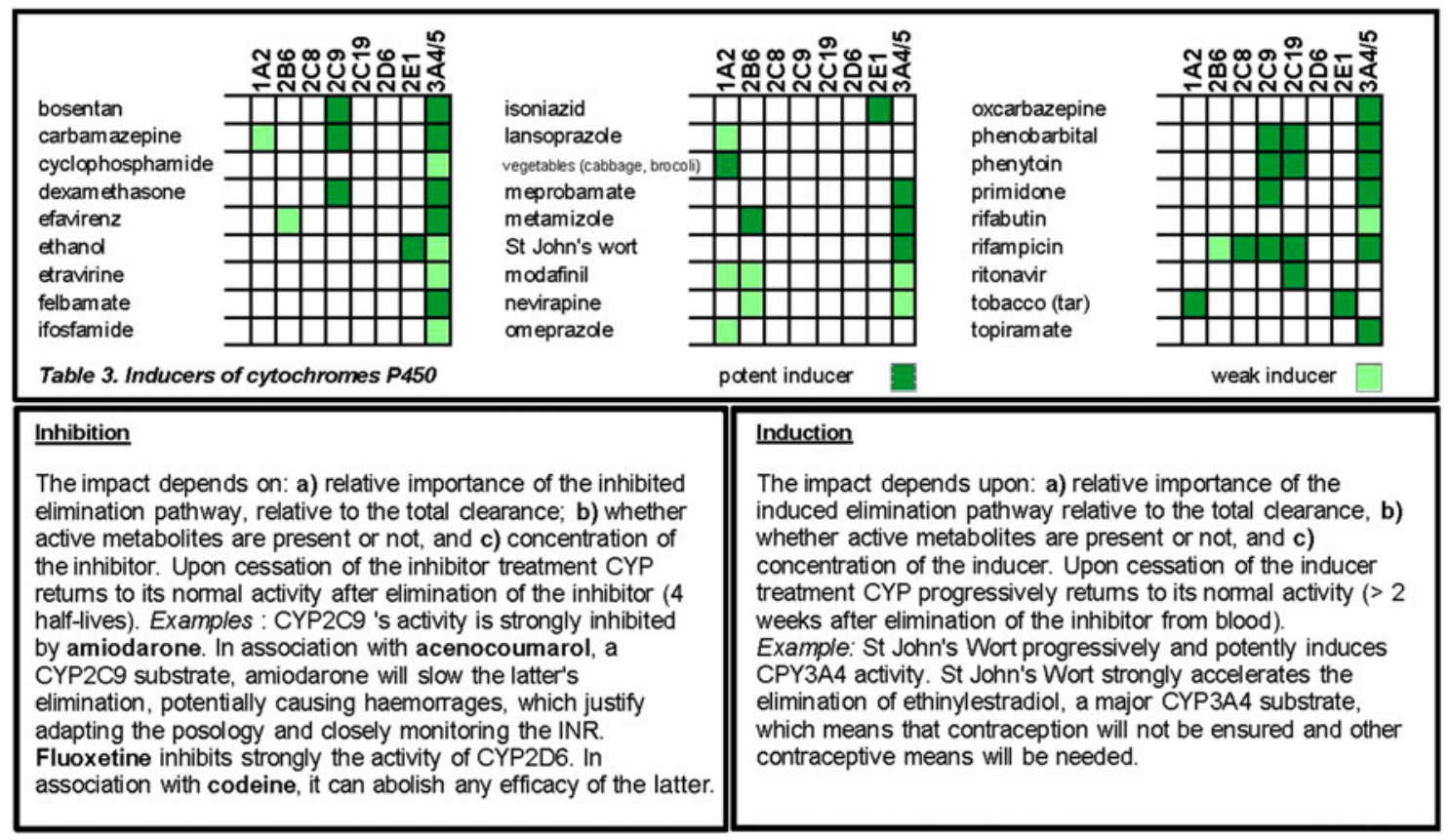




\subsubsection{Psychotropic Agents}

Various psychotropic agents are metabolised at least in part by CYP2D6. Depending on the pharmacokinetic (PK) and the pharmacodynamic ( $\mathrm{PD}$ ) properties of the drug, the impact of the polymorphism will be more or less pronounced. UMs may require higher doses to achieve therapeutic drug levels and effects, whereas PMs might be at increased risk of toxicity. The association between CYP2D6 PM phenotype and psychotropic agent toxicity (antidepressants, antipsychotics) has been described [19, 20]. PMs were twice as frequent amongst patients presenting ADRs (44 vs $21 \%$ ) [19]. Patients treated with CYP2D6 substrates (tricyclics, thioridazine, perphenazine, haloperidol, risperidone) experienced a higher rate of ADRs that was in turn associated with the CYP2D6 genotype ( $\mathrm{PM}>\mathrm{IM}>\mathrm{EM}>\mathrm{UM}$ ) [20]. The costs associated with the treatment of the metabolic extremes (PM and UM) were US $\$ 4,000$ to 6,000 per year higher than those of EM and IM on the same treatments, and the length of hospitalisation was also longer in PMs [20]. Kirchheiner et al. systematically analysed all pharmacogenetic data available on the impact of genetic polymorphisms on the positive effects of and adverse reactions to 36 antidepressants and 38 antipsychotics. CYP2D6 polymorphism was found to be relevant for 14 out of 36 antidepressants, requiring at least doubling of the dose in EMs in comparison to PMs, and for one third of the assessed antipsychotics [21].

2.1.1.1 Antidepressants Most antidepressants, selective serotonin recapture inhibitors (SSRIs), non-selective recapture inhibitors (NSRIs) or tricyclic agents (TCAs) are metabolised by CYP2D6. The UM phenotype is now recognised as a cause of therapeutic "resistance or inefficacy" and higher antidepressant doses are necessary to obtain efficacy [22]. The relationship between persistent mood disorders and CYP2D6 gene duplication was investigated in 108 patients. UM subjects were over-represented in the non-responders group as compared to control population [23]. On the other hand, the clearances of nortriptyline, clomipramine, desipramine, imipramine, trimipramine, amitriptyline, paroxetine, fluvoxamine, fluoxetine and venlafaxine are reduced in PMs [18, 24]. In a prospective study, all the patients experiencing toxicity (confusion, sedation, orthostatic hypotension) after desipramine administration (100 mg/day for 3 weeks) were PMs and the dose consequently had to be reduced [25]. An association between the PM phenotype and venlafaxine cardiotoxicity (palpitation, shortness of breath, arrhythmia) [24] and amitriptyline toxicity [26] was furthermore suggested. The antidepressant effective dose was shown to vary between the two extremes PM and UM from 10 to up to $500 \mathrm{mg} /$ day for nortriptyline, $10-500 \mathrm{mg} /$ day for amitriptyline and $25-300 \mathrm{mg} /$ day for clomipramine [24]. In Asian populations (mostly IMs), it was demonstrated that metabolism of some antidepressants (desipramine, nortriptyline, clomipramine) was reduced and that they received lower antidepressant doses [24]. Kirchheiner et al. developed the first antidepressant dose recommendations based on CYP2D6 genotype/phenotype and PK parameters in Caucasians. The mean dose reduction was $50-80 \%$ for some tricyclics in PMs, and $30 \%$ for some SSRIs. In UMs, the recommended increase in dose was $260 \%$ for desipramine, $300 \%$ for mianserin and $230 \%$ for nortriptyline [27].

The Pharmacogenetics Working Group of the Royal Dutch Pharmacists Association established dose recommendations for several TCAs, SSRIs and NSRIs on the basis of CYP2D6 genotype [28] (Table 3). Clomipramine, imipramine and nortriptyline dose should be reduced by 50-70 \% in PMs and plasma concentrations should be monitored, whereas in UMs an alternative drug may be considered, plasma concentrations monitored or dose increased. No dose adjustment is necessary for paroxetine in PMs and insufficient data are available in UMs. Regarding venlafaxine, insufficient data are available in PMs and the recommendation is to select an alternative drug or adjust dose to clinical response and monitor plasma concentration. In UMs, authors recommend to be alert to decreased venlafaxine and increased $O$-desmethyl-venlafaxine plasma concentration, and to titrate the dose to a maximum of $150 \%$ of the normal dose or select an alternative drug. Regarding duloxetine, no recommendations exist at this time. Insufficient data are available to allow calculation of dose adjustment for the other molecules.

2.1.1.2 Neuroleptics The PM phenotype has been associated with a reduction of the elimination of various antipsychotics such as haloperidol, perphenazine and zuclopenthixol. Their clearance decreased (two- to threefold) in CYP2D6 PMs and their half-life was prolonged [29]. A prospective multicentric study in 175 patients with psychotic symptoms treated with haloperidol demonstrated an inverse correlation between therapeutic efficacy and the number of active CYP2D6 genes and ADRs were more frequent in PMs [30]. In a retrospective study, during the first days of treatment with phenothiazine or haloperidol, $33 \%$ of the patients with severe side effects were PMs [29]. In older patients with dementia treated by perphenazine, side effects were also more frequent in PMs after 10 days of treatment [29]. Deficient CYP2D6 alleles were more prevalent in patients with tardive dyskinesia and parkinsonism on neuroleptics and pseudo-parkinsonism was significantly more frequent in PMs after haloperidol treatment $[29,30]$. These authors suggested that PMs 
should receive half the dose of haloperidol. Furthermore, PMs have been shown to be at fourfold higher risk of starting anti-parkinsonism treatment after being treated with antipsychotics metabolised by CYP2D6 [30]. However, a study estimated that 20 patients would have to be genotyped so that 1 patient would benefit from the treatment [31]. Another retrospective study (241 patients) showed that anti-parkinson drugs were given twice as frequently in PMs [32]. In Asians, haloperidol and clozapine doses were shown to be lower than those in Caucasians, and toxicity appeared at a lower dose [24]. A meta-analysis of eight case-control studies including 569 patients (220 cases with tardive dyskinesia and 349 controls) aimed at evaluating the association between CYP2D6 alleles and susceptibility to tardive dyskinesia in treated schizophrenia. PMs had a $43 \%$ higher risk of developing tardive dyskinesia as compared to EMs [odds ratio $(\mathrm{OR})=1.43,95 \%$ confidence interval $(\mathrm{CI})$ 1.06-1.93, $P=0.021$ ] [33]. The Pharmacogenetics Working Group of the Royal Dutch Pharmacists Association established dose recommendations for haloperidol, risperidone and zuclopenthixol on the basis of CYP2D6 genotype [28] (Table 3). Dose should be reduced by $50 \%$ in PMs or an alternative drug selected, whereas in UMs the authors recommend to be extra alert to diminished plasma concentrations or to select an alternative drug. No dose adjustment is needed for aripiprazole, clozapine, flupentixol and olanzapine.

\subsubsection{Opioids}

The influence of CYP2D6 polymorphisms on the analgesic response and therapeutic outcome to a number of prodrug opioids is now established. The opioids codeine, tramadol and oxycodone have to be activated by CYP2D6 into their active moieties, morphine [34, 35], $O$-desmethyl-tramadol (M1) [36] and oxymorphone [37, 38], respectively. The impact of CYP2D6 polymorphisms have been assessed in terms of PK and PD consequences.

In PMs for CYP2D6, reduced or absent metabolite formation and reduced analgesic effects have been observed after codeine [39], tramadol [40] and oxycodone administration [37, 38]. A cohort study showed that children having ineffective pain treatment of sickle cell crisis with codeine were more likely to have reduced CYP2D6 activity [39]. After major abdominal surgery, non-response rates to tramadol were fourfold higher amongst PMs than other CYP2D6 genotypes in a randomised prospective study [40]. In healthy volunteers, PMs experienced no analgesic effect after oxycodone administration in the experimental pain setting [38].

Conversely the CYP2D6 UM phenotype has been associated with quicker analgesic effects but higher mu-opioid-related toxicity after tramadol [41, 42] or oxycodone administration [38, 43]. The risk of codeine use in paediatrics and breastfed neonates in association with UM genotype has been reported with four fatal cases and serious toxicity cases [44-49]. The FDA released a warning in August 2007 that codeine use by nursing mothers may increase toxicity in infants [50], and more recently about the risk of death after the use of codeine in infants for tonsillectomy/adenoidectomy in August 2012 [51]. In February 2013, the FDA stated that a new Boxed Warning and Contraindication were to be added to the drug label of codeine-containing products [52].

Clinical Pharmacogenetics Implementation Consortium (CPIC) guidelines for codeine therapy in the context of CYP2D6 phenotype were recently published [53]. CPIC was established in order to provide drug-dosing guidelines based on an individual's genotype. These peer-reviewed gene-drug guidelines are published and updated periodically on the PharmGKB website [54]. The authors recommendation is to avoid codeine use in UM and PM for CYP2D6 and consider alternative analgesics such as morphine. The classification of recommendation is labelled as "strong". The Dutch Pharmacogenetics Working Group Guideline edited the same recommendation for codeine, tramadol and oxycodone [28].

CYP activity is modulated by inhibitors mimicking a genetic deficiency (PM phenotype) (Table 2). CYP2D6 inhibitors such as quinidine have been associated with a reduction of codeine, tramadol and oxycodone analgesic effects [34, 36, 38]. Importantly, drug interactions modulating the activity of the enzymes involved in the other pathways of elimination have to be taken into account. Indeed, they have the ability to modify the therapeutic index of a drug or its pharmacological properties, especially in the context of a genetic polymorphism. The co-administration of oxycodone with the CYP3A inhibitor ketoconazole (Table 2) has been associated with a dramatic increase in oxycodone efficacy (experimental pain setting) and toxicity, with this effect being even more pronounced in the UM for CYP2D6 [38]. Similarly a CYP3A inhibitor co-administrated with codeine induced a life-threatening opioid intoxication in a CYP2D6 UM [55].

The pharmacological properties of the dual opioidergic and monoaminergic tramadol [56] may also be modified as a consequence of CYP activity modulation by drug interactions and/or genetic polymorphisms. In CYP2D6 PMs, tramadol properties will move towards a monoaminergic antidepressant-like molecule devoid of opioidergic activity, whereas the opioidergic properties will be more pronounced in CYP2D6 UM. Different pharmacological effects will therefore be expected depending on the activity of CYP2D6. Some authors have summarised recommendations on the usage of opioids while administrating CYP3A and 2D6 inhibitors, and CYP3A inducers [57] 
Table 3 Summary of the consensus guidelines for dose recommendation based on CYP450 pharmacogenetic testing

\begin{tabular}{|c|c|c|}
\hline $\begin{array}{l}\text { Drug/therapeutic } \\
\text { class }\end{array}$ & CYP & Dose recommendation \\
\hline Codeine & CYP2D6 & 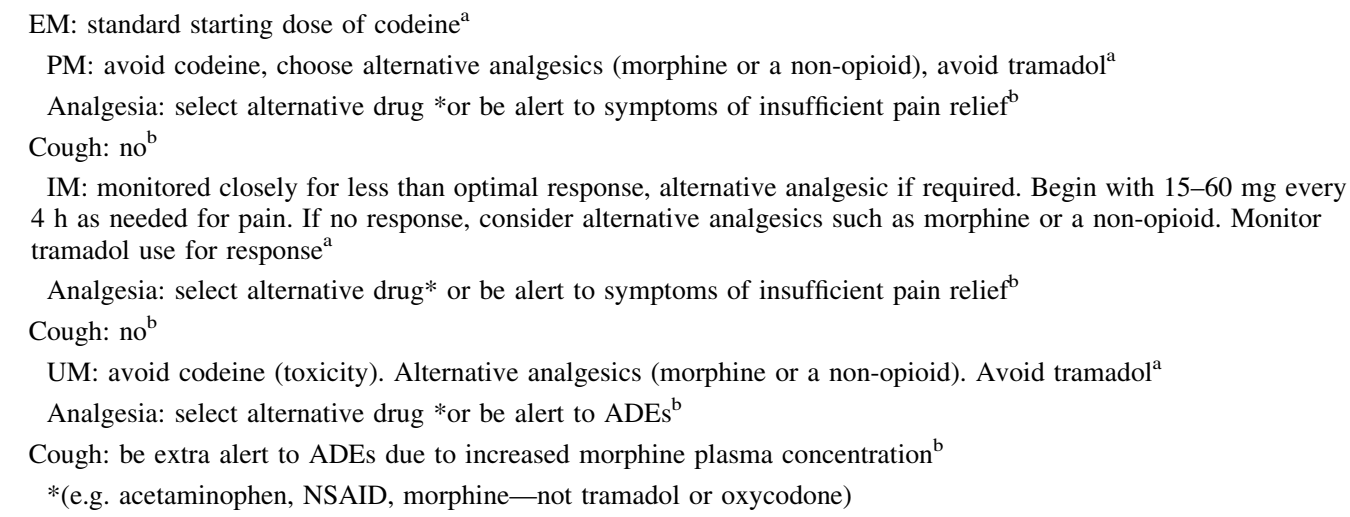 \\
\hline Oxycodone & CYP2D6 & $\begin{array}{l}\text { PM: alternative drug (not tramadol or codeine) or be alert to symptoms of insufficient pain relief } \\
\text { UM: be alert to ADEs }\end{array}$ \\
\hline Tramadol & CYP2D6 & $\begin{array}{l}\text { PM and IM: alternative drug (not oxycodone or codeine) and/or be extra alert to insufficient pain relief } \\
\text { UM: dose reduction by } 30 \% \text {, be alert for ADEs, or alternative drug (not oxycodone or codeine) }{ }^{\mathrm{b}}\end{array}$ \\
\hline Antiarrythmics & CYP2D6 & $\begin{array}{l}\text { Metoprolol and propafenone }{ }^{\mathrm{b}} \\
\text { PM: dose reduction by } 70-75 \% \text { or alternative drug, record ECG, monitor plasma concentration } \\
\text { IM: dose reduction by } 50 \% \text { or alternative drug } \\
\text { UM: alternative drug or titration to a maximum of } 250 \% \text { of the normal metoprolol dose; insufficient data to allow } \\
\text { propafenone dose adjustment calculation but adjust to plasma concentration, record ECG or select alternative drug } \\
\text { Flecainide } \\
\text { PM: dose reduction by } 50 \% \text {, record ECG, monitor plasma concentration } \\
\text { IM: dose reduction by } 25 \% \text {, record ECG, monitor plasma concentration } \\
\text { UM: dose reduction and monitor plasma concentration or select alternative drug (e.g. sotalol, disopyramide, } \\
\text { quinidine, amiodarone) } \\
\text { Carvedilol } \\
\text { No recommendation at this time }\end{array}$ \\
\hline Antidepressants & CYP2D6 & $\begin{array}{l}\text { Clomipramine and imipramine } \\
\text { Dose should be reduced by } 50 \text { to } 70 \% \text { in PMs and plasma concentrations should be monitored; in UM an alternative } \\
\text { drug (*e.g. citalopram, sertraline) may be considered, plasma concentrations monitored or increase imipramine dose } \\
\text { by } 70 \% \text { b } \\
\text { Amitriptyline } \\
\text { PM and UM: select alternative drug* or monitor plasma concentration } \\
\text { IM: dose reduction by } 25 \% \text { and monitor plasma concentration or select alternative drug*b } \\
\text { Nortriptyline } \\
\text { PM (IM): reduce dose by } 60 \text { (40) } \% \text { and monitor plasma concentrations } \\
\text { UM: select alternative drug } *^{\mathrm{b}} \text { or increase dose by } 60 \% \text { and monitor plasma concentrations }{ }^{\mathrm{b}} \\
\text { Venlafaxine } \\
\text { PM, IM: insufficient data to allow calculation of dose adjustment, select an alternative drug or adjust dose to clinical } \\
\text { response and monitor plasma concentration } \\
\text { UM: titrate dose to a maximum of } 150 \% \text { of the normal dose or select an alternative drug*b } \\
\text { Doxepine } \\
\text { PM (IM): reduce dose by } 60 \text { (20) } \% \text {. Monitor plasma concentration } \\
\text { UM: select alternative drug* or increase dose by } 100 \%{ }^{\mathrm{b}} \\
\text { Paroxetine } \\
\text { PM, IM: no dose adjustment } \\
\text { UM: select alternative drug*b } \\
\text { Duloxetine, mirtazapine } \\
\text { No dose adjustment recommendations }\end{array}$ \\
\hline
\end{tabular}


Table 3 continued

\begin{tabular}{|c|c|c|}
\hline $\begin{array}{l}\text { Drug/therapeutic } \\
\text { class }\end{array}$ & CYP & Dose recommendation \\
\hline Antipsychotics & CYP2D6 & $\begin{array}{l}\text { Risperidone } \\
\text { All genotypes: select alternative (e.g. quetiapine, olanzapine, clozapine) or be extra alert to ADE and adjust dose to } \\
\text { clinical response }{ }^{\mathrm{b}} \\
\text { Aripriprazole } \\
\text { PM: reduce maximum dose to } 10 \mathrm{mg} / \mathrm{day} \\
\text { IM, UM: no recommendation } \\
\text { Zuclopenthixol } \\
\text { PM: reduce dose by } 50 \% \text { or select alternative drug } \\
\text { IM: reduce dose by } 25 \% \text { or select alternative } \\
\text { UM: insufficient data to allow calculation of dose adjustment, be alert to low plasma concentrations or select } \\
\text { alternative } \\
\text { Haloperidol } \\
\text { PM: reduce dose by } 50 \% \text { or select alternative (e.g. pimozide, flupenthixol, fluphenazine, quetiapine, olanzapine, } \\
\text { clozapine) } \\
\text { IM: none } \\
\text { UM : insufficient data to allow calculation of dose. Be alert to decreased haloperidol plasma concentration and adjust } \\
\text { maintenance dose in response to haloperidol plasma concentration or select alternative } \\
\text { Clozapine, flupentixol and olanzapine } \\
\text { No dose adjustment needed }\end{array}$ \\
\hline Tamoxifen & CYP2D6 & $\begin{array}{l}\text { PM, IM: consider using aromatase inhibitors for postmenopausal women (IM: avoid concomitant CYP2D6 inhibitor } \\
\text { use) } \\
\text { UM: no recommendation }{ }^{\mathrm{b}}\end{array}$ \\
\hline Anticoagulants & CYP2C9 & $\begin{array}{l}\text { Warfarin: } \\
\text { Two algorithms estimating stable warfarin dose across different ethnic populations [Articles: 18305455, 19228618] } \\
\text { Daily warfarin doses recommendations based on CYP2C9 and VKORC1 genotype (warfarin product insert approved } \\
\text { by the FDA) } \\
\text { Acenocoumarol } \\
* 1 / * 2 \text { : check INR more frequently }{ }^{\mathrm{b}} \\
* 2 / * 2, * 1 / * 3, * 2 / * 3, * 3 / * 3 \text { : check INR more frequently after initiating or discontinuing NSAIDs }{ }^{\mathrm{b}} \\
\text { Phenprocoumon } \\
* 1 / * 2, * 1 / * 3 \text { : none } \\
* 2 / * 2, * 2 / * 3, * 3 / * 3 \text { : check INR more frequently }\end{array}$ \\
\hline Phenytoin & CYP2C9 & $\begin{array}{l}* 1 / * 2, * 1 / * 3 \text { : maintenance dose reduction by } 25 \%^{\mathrm{b}} \\
* 2 / * 2, * 2 / * 3, * 3 / * 3 \text { : maintenance dose reduction by } 50 \%^{\mathrm{b}} \\
\text { Evaluate response and serum concentration after } 7-10 \text { days. Be alert to ADEs (e.g. ataxia, nystagmus, dysarthria, } \\
\text { sedation) }\end{array}$ \\
\hline Sulfonylureas & CYP2C9 & $\begin{array}{l}\text { Glibenclamide, glimepiride, gliclazide, tolbutamide } \\
\text { No adaptation of dosage is recommended }{ }^{\mathrm{b}}\end{array}$ \\
\hline Clopidogrel & CYP2C19 & $\begin{array}{l}\text { UM, EM: clopidogrel label-recommended dosage and administration }{ }^{\mathrm{a}, \mathrm{b}} \\
\text { IM, PM: prasugrel or other alternative therapy (if no contraindication) } \\
\text { Consider alternative drug. Prasugrel is not, or to a much smaller extent, metabolised by CYP2C19 but is associated } \\
\text { with an increased bleeding risk compared to clopidogrel }^{\mathrm{b}}\end{array}$ \\
\hline $\begin{array}{l}\text { Proton pump } \\
\text { inhibitors }\end{array}$ & CYP2C19 & $\begin{array}{l}\text { Esomeprazole, lansoprazole, omeprazole, pantoprazole } \\
\text { UM: be extra alert to insufficient response, dose increase by } 50-400 \%^{\mathrm{b}} \\
\text { PM, IM: no dose recommendation }{ }^{\mathrm{b}} \\
\text { Rabeprazole } \\
\text { No dose recommendation }^{\mathrm{b}}\end{array}$ \\
\hline
\end{tabular}


Table 3 continued

\begin{tabular}{|c|c|c|}
\hline $\begin{array}{l}\text { Drug/therapeutic } \\
\text { class }\end{array}$ & CYP & Dose recommendation \\
\hline \multirow[t]{13}{*}{ Antidepressants } & \multirow[t]{13}{*}{ CYP2C19 } & Citalopram, escitalopram ${ }^{\mathrm{b}}$ \\
\hline & & $\begin{array}{l}\text { UM: monitor plasma concentration and titrate dose to a maximum of } 150 \% \text { in response to efficacy and adverse drug } \\
\text { event or select alternative drug (e.g. fluoxetine, paroxetine) }\end{array}$ \\
\hline & & PM and IM: none \\
\hline & & Sertraline $^{\mathrm{b}}$ \\
\hline & & PM: reduce dose by $50 \%$ \\
\hline & & $\begin{array}{l}\text { IM: insufficient data to allow calculation of dose adjustment. Be extra alert to adverse drug events (e.g. nausea, } \\
\text { vomiting, diarrhoea) }\end{array}$ \\
\hline & & UM: none (no data were retrieved) \\
\hline & & Imipramine $^{\mathrm{b}}$ \\
\hline & & $\begin{array}{l}\text { PM: reduce dose by } 30 \% \text { and monitor plasma concentration of imipramine and desipramine or select alternative } \\
\text { drug (e.g. fluvoxamine, mirtazapine) }\end{array}$ \\
\hline & & IM: insufficient data to allow calculation of dose adjustment. Select alternative drug (e.g. fluvoxamine, mirtazapine) \\
\hline & & UM: no data \\
\hline & & Moclobemide $^{\mathrm{b}}$ \\
\hline & & No recommendations at this time \\
\hline Voriconazole & CYP2C19 & $\begin{array}{l}\text { PM or IM: monitor serum concentration } \\
\text { UM: none }\end{array}$ \\
\hline
\end{tabular}

ADEs adverse drug events, $C Y P$ cytochrome P450, EM extensive metaboliser, $U M$ ultrarapid metaboliser, $I M$ intermediate metaboliser, $P M$ poor metaboliser, INR international normalised ratio, FDA US Food and Drug Administration

a According to the Clinical Pharmacogenetics Implementation Consortium of the Pharmacogenomics Research Network (CPIC)

b According to the Pharmacogenetics Working Group of the Royal Dutch Pharmacists Association

(Table 2). The recommendation is to avoid the combination of oxycodone and CYP3A inhibitors as well as CYP3A inducers and to monitor patients on oxycodone with a CYP2D6 inhibitor. Regarding codeine, the authors' recommendations are to avoid the co-administration of a CYP2D6 inhibitor or consider alternative pain treatment, and to monitor if administration is concomitant with a CYP3A inhibitor or inducer. Codeine should be avoided when a CYP3A inhibitor is co-prescribed in a highly susceptible population (such as UM for CYP2D6) [57]. The importance of these pharmacogenetic modulations of drug interactions in the clinical setting needs to be further investigated.

\subsubsection{Antiarrhythmic Agents}

CYP2D6 is involved in the metabolism of carvedilol, bufuralol, metoprolol, propranolol and timolol. CYP2D6 genetic polymorphism has an impact on the disposition of metoprolol, bufuralol and timolol, whereby PMs have a higher exposure (four- to sixfold), higher plasma concentrations (two- to fivefold) and a prolonged half-life (two- to threefold). The PM genotype has furthermore been associated with an increased risk of toxicity after metoprolol administration $[22,58]$ and some authors demonstrated that PMs had a fivefold higher risk of developing adverse effects [59]. The increased efficacy or higher risk of toxicity in PMs was furthermore demonstrated after timolol (more pronounced heart rate reduction) [60], carvedilol (reduction of the systolic blood pressure) [61], propafenone (central side effects five times more pronounced and increased QRS narrowing at a given concentration) administration [62]. After propranolol administration, an open study did not show any difference in the PK parameters or the clinical response depending on CYP2D6 phenotype [60]. The Dutch Pharmacogenetics Working Group Guideline recommended a 70-75\% reduction of metoprolol and propafenone in PMs or alternative drug selection [28]. In UMs, an alternative drug should be selected or metoprolol dose titrated to a maximum of $250 \%$ of the normal dose. Insufficient data are available to allow calculation of dose adjustment for propafenone but the recommendation is to adjust dose to plasma concentration and record ECG or select an alternative drug.

A double-blind randomised control study assessed the PK and PD consequences of concomitant administration of carvedilol and a CYP2D6 inhibitor (fluoxetine) in cardiac failure. Fluoxetine stereospecifically inhibited $(R)-(+)-$ carvedilol, but had no clinical impact on the side effects, heart rate and blood pressure in this pilot study [63]. In healthy volunteers receiving metoprolol, after the co-administration of the CYP2D6 inhibitor paroxetine 
$20 \mathrm{mg} /$ day, both $(S)$ - and $(R)$-metoprolol AUC increased three- and fourfold, respectively, and the half-life of both isomers increased by approximately twofold. The decreases of the heart rates and systolic blood pressures were significantly more pronounced after paroxetine administration [64]. Similarly, acute myocardial infarction patients treated with metoprolol and paroxetine had a significant metoprolol AUC increase, and a reduction of metoprolol dose was required in two patients owing to excessive bradycardia and severe orthostatic hypotension [65].

\subsubsection{Tamoxifen}

Tamoxifen is approved in the treatment of metastatic breast cancer as well as an adjuvant therapy of breast cancer in postmenopausal women. The two active metabolites of tamoxifen produced predominantly by CYP2D6 as well as CYP3A are 4-hydroxytamoxifen and endoxifen; their affinity for the oestrogen receptor is 100 times higher than tamoxifen and their potency is 30 - to 100 -fold greater [66, 67]. Endoxifen is considered the most clinically relevant active metabolite in terms of anticancer effect and hormone receptor blockade. Endoxifen plasma concentrations in newly diagnosed breast cancer CYP2D6 PM and IM genotyped women were 26 and $55 \%$ of those in EMs, respectively [68]. The same was shown in CYP2D6 PMs owing to drug inhibition by paroxetine [69]. Thirty-nine and $9 \%$ of the variability of steady-state concentrations of endoxifen and 4-hydroxytamoxifen, respectively, were explained by CYP2D6 genotypes and among PMs $93 \%$ had endoxifen levels below $\mathrm{IC}_{90}$ values [70]. PMs are therefore likely to experience therapeutic failure after tamoxifen, whereas UMs might be prone to increased toxicities [71]. Homozygous CYP2D6*4 carriers (PMs) were shown to have increased risk of breast cancer recurrence, shorter relapse-free periods and worse event-free survival rates as compared to carriers of functional alleles [72-74]. The impact of CYP2D6*10 homozygotes (IMs) on the PK and PD behaviour of tamoxifen was assessed in Asians [75-78] . CYP2D6*10/*10 has lower endoxifen and 4-OH-tamoxifen concentrations, shorter median time to progression, and higher incidence of recurrence within 10 years after the operation. The FDA has recommended labelling change to indicate that postmenopausal oestrogen receptor-positive breast cancer patients taking adjuvant tamoxifen who are homozygous for $C Y P 2 D 6^{*} 4$ have a significant decreased relapse-free survival as compared to other genotypes. However no recommendation on the routine testing of all women on tamoxifen was made, and the impact of other deficient variants (such as $C Y P 2 D 6^{*} 10$ ) was not addressed. A matched case-control study using the Austrian Breast and Colorectal Cancer Study Group Trial 8
(ABCSG8) demonstrated that PMs or carriers of a deficient allele had a higher likelihood of an event than EMs (OR 2.45 and 1.67 , respectively) during the first 5 years of therapy [79].

In 98 Japanese breast cancer patients on $20 \mathrm{mg}$ tamoxifen daily (adjuvant setting), Kiyotani et al. evaluated the impact of dose adjustment according to CYP2D6 genotype. In $C Y P 2 D 6^{*} 10$ heterozygotes and homozygotes, the dose was increased to 30 and $40 \mathrm{mg} / \mathrm{day}$, respectively. The achieved endoxifen and 4-OH-tamoxifen plasma concentrations were increased to similar levels as those in the CYP2D6*1/*1 patients receiving tamoxifen $20 \mathrm{mg} /$ day [80]. The dose increase did not result in increased side effects. However the dose increase did not lead to doseproportional increase in endoxifen concentrations. Others authors demonstrated that increasing the tamoxifen dose from 20 to $40 \mathrm{mg} /$ day resulted in increased endoxifen concentrations in PMs but not in EMs [81]. Another study demonstrated that increasing tamoxifen dose from 20 to $30 \mathrm{mg}$ in PMs was associated with a $90 \%$ in the endoxifen levels by day 60 and an increased antioestrogenic activity score [82].

Conflicting results have been reported regarding the association between CYP2D6 genotype and tamoxifen effects. The pitfalls of these retrospective studies (small cohorts, limited CYP2D6 allele coverage, quality of genotyping, correct genotype-phenotype assignment) were pointed out by several authors [83, 84]. Two large prospective studies (The Breast International Group BIG 1-98 trial and the Arimidex, Tamoxifen, Alone or in Combination (ATAC) trial) were unsupportive with regard to CYP2D6 genotyping in the adjuvant setting as no association was demonstrated with breast cancer recurrence [85, 86]. However these two studies have been criticised as endoxifen plasma concentrations were not measured and drug inhibition was not taken into account (Table 2). Pharmacogenetics experts asked for the retraction of the BIG 1-98 study on the basis of massive departures from Hardy-Weinberg equilibrium with the possibility of bias introduced by the CYP2D6 genotype from the tumour (somatic) and not the host genome (germline DNA) [83, 87]. Some authors have therefore stated that "until prospective adjuvant trial data are available, the current evidence is sufficient to accept the CYP2D6-tamoxifen pharmacogenetic relationship in postmenopausal women" [83]. Therefore CYP2D6 genotyping may be useful in selecting adjuvant hormonal therapy in postmenopausal women and aromatase inhibitors might be preferred in CYP2D6 PMs as recommended by the Pharmacogenetics Working Group of the Royal Dutch Pharmacists Association. Medications decreasing CYP2D6 activity, such as antidepressants, should be avoided when prescribing tamoxifen (Table 3). This needs to be confirmed in well- 
conducted prospective studies with tamoxifen adjuvant therapy.

\subsection{Cytochrome P450 2C19}

The CYP2C19 is responsible for metabolising commonly used drugs that include clopidogrel, proton pump inhibitors (PPIs) and some antidepressants [11, 88]. The enzyme is highly polymorphic. To date, at least $35(* 1 \mathrm{~B}$ to $* 28)$ variants and a series of subvariants of $C Y P 2 C 19$ have been identified, CYP $2 C 19 * 1$ representing the wild-type allele [89]. On the basis of their ability to metabolise $(S)$ mephenytoin or other probe drugs, individuals can be categorised as EM, PM or UM for CYP2C19 [90, 91]. Heterozygous EMs are sometimes also referred to as IMs. The majority of the CYP2C19 PMs are carriers of the variant alleles $* 2$ and $* 3$, which are loss of function alleles (LOF) [90], whereas the $* 17$ variant is a gain of function (GOF) allele associated with increased activity [91]. Studies have shown a marked interethnic variation in the distribution of variant alleles. The allelic frequency of CYP2C19*2 has been shown to be $15 \%$ in Africans, $29-35 \%$ in Asians, $12-15 \%$ in Caucasians and $61 \%$ in Oceanians. The CYP $2 C 19 * 3$ is mainly found in Asians (5-9\% in Asians, less than $0.5 \%$ in Caucasians). The allelic frequency of $C Y P 2 C 19 * 17$ has been shown to be $16 \%$ in Africans, 3-6\% in Asians and 16-21\% in Caucasians [92, 93].

\subsubsection{Clopidogrel}

Clopidogrel is a prodrug whose in vivo metabolite binds to the platelet $\mathrm{P}_{2} \mathrm{Y}_{12}$ receptor causing irreversible blockade. Approximately $85 \%$ of the parent drug is inactivated by human carboxylesterase 1 , whereas the remainder is transformed to the intermediate, inactive oxo-clopidogrel by CYP2C19, CYP1A2 and CYP2B6. The CYP3A, CYP2B6, CYP2C9 and CYP2C19 are responsible for the second-step production of the active metabolite [94]. Many studies have shown that carriers of certain variant alleles exhibit a reduced capacity to produce the active metabolite and are therefore at increased risk of adverse cardiovascular events [92]. In 2010, the FDA added a Boxed Warning to the clopidogrel label to emphasis that patients who are PM for CYP2C19 are at an increased risk of adverse cardiovascular outcomes because of a reduced effectiveness of clopidogrel [95]. Bauer et al. [96] recently conducted a systematic review and meta-analysis to examine the association between CYP2C19 genotype and the clinical efficacy of clopidogrel, in a total of 15 studies. The presence of at least one LOF allele was associated with an increased risk of stent thrombosis (summary OR 1.77; $95 \%$ CI 1.31-2.40; $P<0.001)$. However, the authors did not find an association between $C Y P 2 C 19$ polymorphism (LOF or GOF allele) and the clinical efficacy of clopidogrel used to prevent major adverse cardiovascular events (OR 1.11; $95 \%$ CI $0.89-1.39 ; P=0.36$ for carriers of at least one LOF allele, and OR 0.93; $95 \%$ CI $0.75-1.14 ; P=0.48$ for carriers of a GOF allele). In contrast, in a more recent metaanalysis that included 16 studies, the presence of at least one LOF allele was associated with a significant increase in adverse clinical events which were defined as a composite endpoint of death, myocardial infection, stent thrombosis or ischaemic stroke (OR 1.42; 95 \% CI 1.13-1.78) [97]. Evidence supports an effect of CYP2C19 genotype on protection from major adverse cardiovascular outcomes for acute coronary syndrome/percutaneous coronary intervention, but not for lower-risk conditions [98]. Therefore, despite the large number of studies published, guiding clopidogrel dosing on the basis of CYP2C19 genotype is still a matter of debate [99] (Table 3).

\subsubsection{Proton Pump Inhibitors}

Proton pump inhibitors are used to treat acid-related disorders such as gastro-oesophageal reflux disease or oesophagitis/gastritis. Furthermore, PPIs are the treatment of choice for Helicobacter pylori infection, in combination with antibiotics. They undergo hepatic metabolism via the CYP450 pathways and the isoforms CYP2C19 and CYP3A4 in particular [100]. As a result of the metabolic pathways of PPIs, CYP2C19 polymorphism has an impact on their PK behaviour and clinical efficacy. The PK properties of PPIs (AUC, $C_{\max }$ and clearance) have been shown to be significantly different between CYP2C19 PMs and EMs. The ratios of the mean AUC values in PMs versus EMs for omeprazole, pantoprazole, lansoprazole and rabeprazole were $6.3,6,4.3$ and 1.8 , respectively [101]. These differences in terms of PK properties translate into differences in their clinical effects. It has been shown that the mean intragastric $\mathrm{pH}$ values were higher in PMs than in EMs for both omeprazole and lansoprazole [102]. A meta-analysis, which included 20 studies, showed a significant difference in $H$. pylori eradication rates between wild-type individuals and carriers of at least one LOF allele (OR 2.26; $95 \%$ CI 1.58-2.96; $P<0.0001$ ) when all PPIbased therapies were combined. The difference was greater when wild-type homozygous and variant homozygous patients were compared (OR 2.79; $95 \%$ CI 1.77-4.41; $P<0.0001)$. When individual agents were analysed separately, a significant difference was observed for omeprazole and lansoprazole, whereas no difference between all genotypes was observed for rabeprazole [103]. This is probably due to the metabolism of rabeprazole which involves a non-enzymatic reduction [101]. 


\subsubsection{Psychotropic Agents}

CYP2C19 is one of the major metabolic pathways for several antidepressants, including imipramine, clomipramine, citalopram, sertraline, fluoxetine, venlafaxine and moclobemide [104]. Imipramine efficacy and adverse effects are associated with the sum of the plasma concentrations of imipramine and its active metabolite desipramine. The formation of the latter is mediated via CYP2C19. Some authors reported an increase in the imipramine/desipramine concentration in CYP2C19 PMs, potentially resulting in an increased frequency of adverse effects. For this reason, a dose reduction of $70 \%$ of the recommended dose or the selection of an alternative drug is warranted [105].

Citalopram is metabolised primarily by CYP2C19 and CYP3A4, and to a lesser extent by CYP2D6 [106]. Differences in the PK properties of citalopram and escitalopram have been reported in CYP2C19 PMs and IMs [88]. However, owing to the large therapeutic window of these antidepressants, this does not appear to result in differences in their side effects. Therefore, a dose adjustment is not considered necessary. However, a recent publication reported a case of escitalopram-induced serotonin syndrome due to CYP2C19 and CYP2D6 genetic polymorphisms and drug-drug interactions with CYP2C19 and CYP3A4 inhibitors [105] (Table 2). Results from the Sequenced Treatment Alternatives to Relieve Depression $($ STAR $* D)$ study, which included more than 1,000 patients, showed that the $* 2$ variant allele was associated with lower odds of tolerance of citalopram (OR 0.60; $95 \%$ CI $0.39-0.91 ; P=0.02)$. Indeed, PMs may achieve high drug serum levels, which in some patients may be associated with lower drug tolerance. In the subset of subjects who were tolerant of citalopram treatment, remission was highest for CYP2C19 PMs, suggesting that PMs who are able to tolerate citalopram may have favourable treatment outcomes [107].

For sertraline, significant differences in PK parameters have been reported in CYP2C19 PMs, requiring a $50 \%$ dose reduction in this population of patients [105].

\subsection{CYP2C9}

CYP2C9 exhibits a genetic polymorphism and, to date, more than 35 allelic variants and a number of subvariants have been described [108]. The two most common allelic variants are $C Y P 2 C 9 * 2$ [109] and $C Y P 2 C 9 * 3$ [110]. Both of these polymorphisms lead to a reduced activity of CYP2C9. These two alleles are carried by approximately $35 \%$ of Caucasians $[111,112]$ but are relatively rare in Asian and African populations [113].

\subsubsection{Vitamin K Antagonists}

CYP2C9 is the major route of metabolism of vitamin $\mathrm{K}$ antagonists such as warfarin, acenocoumarol and phenprocoumone, drugs commonly used for thrombotic complications (deep vein thrombosis, atrial fibrillation, myocardial infarct). Warfarin is metabolised by several cytochromes $\mathrm{P} 450$ but CYP2C9 is the major metabolic pathway. The first correlation between polymorphisms of CYP2C9, warfarin doses and the risk of bleeding was observed in 1999 [114]. In this study, patients with the $C Y P 2 C 9 * 2$ and $C Y P 2 C 9 * 3$ alleles required lower doses of warfarin. This observation has since been reported in many clinical studies [115-117] and seems to be especially noticeable at the beginning of the anticoagulant treatment [118-120]. Stabilisation of treatment is also a parameter that was found to be influenced by polymorphisms of CYP2C9. Among carriers of the CYP2C $9 * 3$ allele, the time to reach treatment stability with warfarin or acenocoumarol is longer [121, 122]. Once the dosage is stabilised, it appears that CYP2C9 polymorphisms influence the effect of oral anticoagulation to a lesser extent [123, 124]. In some studies, it has also been reported that the occurrence of supratherapeutic INRs was higher in patient carriers of these polymorphisms $[122,125]$. The $C Y P 2 C 9^{*} 2$ allele seems to have less influence on the dose of acenocoumarol or phenprocoumon compared to warfarin $[121,122,126$, 127]. However, some studies do show a need for decreased doses of acenocoumarol in $C Y P 2 C 9 * 2$ carriers [128, 129]. Numerous guidelines have been published on the use of pharmacogenomic tests in dosing of warfarin [130]. Two online algorithms are recommended that both provide reliable and very similar results $[54,131]$.

\subsubsection{NSAIDs}

In vitro studies have demonstrated that at least 18 NSAIDs (namely aceclofenac, aspirin, azapropazone, celecoxib, diclofenac, etodolac, flurbiprofen, ibuprofen, indomethacin, lornoxicam, mefenamic acid, meloxicam, naproxen, phenylbutazone, piroxicam, suprofen, tenoxicam and valdecoxib) are metabolised, mainly, or at least in part, by CYP2C9 [132]. To date, the PK or PD consequences of CYP2C9 polymorphisms have been studied for several NSAIDs (celecoxib, diclofenac, flurbiprofen, ibuprofen, lornoxicam, piroxicam and tenoxicam), with the PD studies focusing mainly on adverse effects rather than on efficacy. Results of these different studies are often controversial. A retrospective trial $(n=218)$ assessed the association of polymorphic $C Y P 2 C 9$ alleles and the risk of acute gastrointestinal (GI) bleeding in subjects receiving NSAIDs. The frequency of $C Y P 2 C 9$ polymorphic alleles increased in individuals with NSAIDs-induced acute gastric bleeding. 
The OR for bleeding was 2.5 for heterozygous and 3.7 for homozygous carriers of mutated alleles when compared with non-bleeding subjects. Unexpectedly, this observed risk was associated with the $C Y P 2 C 9 * 2$ allele [133]. Another study $(n=26)$ identified a significantly higher frequency of $C Y P 2 C 9^{*} 1 / * 3$ and $C Y P 2 C 9^{*} 1 / * 2$ carriers in documented NSAID-related gastro-duodenal bleeding versus a matched control group. The presence of $C Y P 2 C 9 * 3$ was associated with a significant higher risk of bleeding (OR 7.3) even though no $C Y P 2 C 9 * 3 / * 3$ carriers were included in the study [134]. A more recent study with a bigger sample $(n=188)$ also concluded that there was an increased risk of GI bleeding when treated with NSAIDs that was linked to the presence of the $C Y P 2 C 9^{*} 3$ allele [135]. However, two other small $(n=23$ and $n=26)$ retrospective studies found no relationship between NSAID-induced gastric ulceration and CYP2C9 genotype. Again, no homozygote $(* 3 / * 3)$ patient was included in the study [136, 137]. Even though risk of GI bleeding is clearly linked to the dose of NSAID and that PK data show a greater exposition to these drugs in carriers of the $C Y P 2 C 9 * 2$ and/or $C Y P 2 C 9 * 3$ alleles, the actual in vivo evidence on augmented risk of GI bleeding is controversial and there is therefore no recommendation of dosage adaptation in mutated patients.

\subsubsection{Sulfonylureas}

Sulfonylureas, such as first-generation tolbutamide and second-generation gliclazide, glyburide (also called glibenclamide) and glimepiride, are oral hypoglycaemic agents used for the treatment of type 2 diabetes. They are mainly metabolised by CYP2C9 [138], with a contribution of CYP2C19 for several of these sulfonylureas [139, 140]. The PK properties of sulfonylureas have been evaluated in few studies. For tolbutamide, mean oral clearances were reduced for all healthy carriers of one or two $* 2$ or $* 3$ alleles, with a clearance of $0.15 \mathrm{l} / \mathrm{h}$ in homozygous carriers of $C Y P 2 C 9^{*} 3$ compared to $0.97 \mathrm{l} / \mathrm{h}$ in wild-type subjects. These PK differences did, however, not affect insulin and glucose concentrations [141]. In homozygous subjects for allele $C Y P 2 C 9 * 3 / * 3$, oral clearance of glyburide was reduced by more than $50 \%$ compared to wild-type subjects and insulin serum levels at $12 \mathrm{~h}$ were significantly higher. Presence of the CYP2C $9 * 2$ allele had only a slight influence on these two parameters [142]. In another study, heterozygous carriers of $C Y P 2 C 9^{*} 3$ showed a median total area under the plasma concentration-time curve of $280 \%$ and of $267 \%$ for the values in $C Y P 2 C 9^{*} 1 / * 1$ carriers for glyburide and glimepiride, respectively [143]. A study conducted on type 2 diabetic patients, treated with either glimepiride, gliclazide or glipizide, showed that carriers of $C Y P 2 C 9^{*} 2$ or $* 3$ alleles were more prone to hypoglycaemic attacks than wild-type subjects but this difference was only significantly associated with gliclazide [144]. Even if there is a clear PK relation between sulfonylureas and CYP2C9 polymorphisms, no adaptation of dosage is recommended because of a mild risk of hypoglycaemia and the possibility to monitor glucose plasma levels [54].

\subsubsection{Angiotensin II Receptor Antagonists}

Angiotensin II receptor antagonists, such as losartan, irbesartan and candesartan, are used in the treatment of hypertension and congestive heart failure. These drugs are metabolised by CYP2C9; in the case of losartan, this metabolism affords an active metabolite. Several studies showed either a lower rate of oxidation of losartan into its metabolite [145], a higher plasma AUC losartan/AUC metabolite ratio [146] or a decreased level of the losartan metabolite [147] in carriers of $C Y P 2 C 9 * 2$ and/or $C Y P 2 C 9 * 3$ alleles. In type 1 diabetic patients with nephropathy, the change in systolic blood pressure was significantly greater in non $* 3$ carriers than in $* 3$ carriers after 4 months [148]. For irbesartan, a study in Chinese patients showed an increased plasma concentration in the $C Y P 2 C 9 * 3$ carriers but without any impact on the hypotensive effect [149]. However, a greater reduction in blood pressure in carriers of the $* 1 / * 2$ and the $* 1 / * 3$ genotypes compared with wild-type subjects was observed with irbesartan in a Swedish population [150]. There is no recommendation for a dose adaptation when these angiotensin II receptor antagonists are prescribed to carriers of mutated alleles of $C Y P 2 C 9$.

\subsubsection{Phenytoin}

Phenytoin is a commonly used antiepileptic drug. It is mainly metabolised by CY2C9 with a minor contribution of CYP2C19. Patient carriers of at least one $C Y P 2 C 9^{*} 2$ or $C Y P 2 C 9 * 3$ allele with plasma concentrations in the therapeutic range needed approximately a third lower daily dose of phenytoin than wild-type patients (199 versus $314 \mathrm{mg} / \mathrm{day}$, respectively) [151]. Similar results were found in Turkish [152], Japanese [153] and Taiwanese populations [154]. Regarding the evaluation of an increased toxicity of phenytoin in CYP2C9 mutated patients, a small study showed an increased incidence of cutaneous reactions among carriers of CYP2C $9 * 3$ compared to wild-type patients [155]. Another study showed an increased risk of neurological adverse reactions (defined as symptoms such as dizziness, nystagmus, ataxia, slurred speech, lethargy and mental confusion) in a Southern Indian population when they were carriers of the $C Y P 2 C 9 * 3$ allele [156]. Dosage adaptation has been recommended for phenytoin in $C Y P 2 C 9$ mutated patients, with a dose reduction of $25 \%$ for $* 1 / * 2$ and $* 1 / * 3$ carriers and of $50 \%$ for $* 2 / * 2, * 2 / * 3$ and $* 3 / * 3$ carriers [28]. 


\section{Genotyping and Phenotyping Techniques}

Besides the quantification of the circulating drug concentrations (therapeutic drug monitoring), two approaches are now available to help personalise drug therapies.

Phenotyping and genotyping tests are used in clinical practice to identify variations in CYP enzymatic activities or $C Y P$ allelic variants. They may help in predicting the right dose for the right patient, and anticipating toxicities or therapeutic inefficacies. Furthermore, they may allow the distinction between a compliance problem and an UM phenotype or between a drug overdose and a metabolic defect.

Genotyping allows precise determination of the individual DNA sequence and analysis of functional genetic mutations coding for specific enzymes. It offers the possibility to predict the phenotype based on the alleles identified providing that the relationship between genotype and phenotype has been established. Genotyping is not yet available for all CYP and its major drawback is the incapacity to measure the influence of the environmental factors such as drug-drug interactions on the enzymatic activity. CYP phenotyping provides information on the real-time (in vivo) activity of CYP enzymes and may therefore provide the most clinically relevant information as it reflects a combination of genetic, environmental and endogenous factors [157].

\subsection{Genotyping}

Classical molecular biology methods analyse one allele at a time and use polymerase chain reaction (PCR) to amplify DNA coupled with post-PCR detection methods such as restriction fragment length polymorphism (RFLP) after hydrolysis with restriction enzymes or fluorescing probes specific for each allele [158]. This implies that only a small subset of variant alleles are usually analysed which can therefore reduce the power of phenotype prediction for some groups of metabolisers. Furthermore the wild-type allele $(* 1)$ is assumed by default and not specifically tested.

Real-time PCR-based assay methods for most clinically important variant genes of CYP2C9, CYP2C19 and CYP2D6 are now available. Depending on the number of SNPs to be screened, multiplexing approaches have also been developed. The microarray technologies offer the advantage of allowing simultaneous determination of various alleles, as well as being rapid, reliable, accurate and easy to perform [159].

\subsubsection{AmpliChip CYP450 GeneChip ${ }^{\circledR}$}

This is an oligonucleotide microarray hybridisation method for genotyping CYP2D6 and $C Y P 2 C 19$ that has been developed by Roche Molecular Systems and Affymetrix. It was the first clinically available tool based on microarray technology and was granted market approval by the FDA in 2004. A total of 15,000 oligonucleotide probes are included in the microarray that allow simultaneous and multiple allele testing for 20 alleles of CYP2D6 $(* 1, * 2, * 3$, $* 4, * 5, * 6, * 7, * 8, * 9, * 10, * 11, * 15, * 17, * 19, * 20, * 29$, $* 35, * 36, * 40$ and $* 41)$ as well as 7 CYP2D6 duplications $(* 1 \times \mathrm{N}, * 2 \times \mathrm{N}, * 4 \times \mathrm{N}, * 10 \times \mathrm{N}, * 17 \times \mathrm{N}, * 35 \times \mathrm{N}$ and $* 41 \times \mathrm{N}$ ) and 3 CYP2C19 alleles $(* 1, * 2$ and $* 3$ ) [160]. The test is based on five major processes: PCR amplification of purified DNA, labelling of the amplified product, hybridisation of the labelled amplified product to a microarray and staining of the bound products, scanning of the microarray and interpretation of the phenotype by software using an algorithm [161]. This test does not determine the exact number of extra copies of CYP2D6 alleles. The overall genotype call rate was $99.3 \%$ for 403 tested samples. The performance of the AmpliChip in predicting CYP2D6 phenotype was assessed $(n=165)$ and an overall $80 \%$ coherence was obtained. Phenotype prediction was optimal for PM (sensitivity and specificity $100 \%$ ) and satisfactory for EM (sensitivity $95 \%$, specificity $47 \%$ ) and IM (sensitivity $42 \%$, specificity $97 \%$ ) but discrepancies were observed for UM prediction (sensitivity $6 \%$, specificity $99 \%$ ) [162].

\subsubsection{Luminex Tag-It Mutation Detection Kit}

The detection kit marketed by Luminex uses a microsphere-based universal array genotyping platform [160]. The Luminex xTAG CYP2D6 kit was approved by the FDA to detect the following alleles: $* 1, * 2, * 3, * 4, * 5, * 6$, $* 7, * 8, * 9, * 10, * 11, * 15, * 17, * 29, * 35, * 41, \times \mathrm{N}$. However it does not specify if the allele is duplicated and it is not associated with phenotype prediction algorithm software. Seven alleles can be detected for CYP2C19 $(* 2, * 3$, and the rare $* 4, * 5, * 6, * 7, * 8$ ), and five alleles for CYP2C9 $(* 2, * 3, * 4, * 5$ and $* 6)$.

\subsection{3 iPLEX ${ }^{\circledR} A D M E$}

Three panels have been developed by Sequenom: PGx panel, CYP2C9/VKORC1 panel and CYP2C19 panel.

The iPLEX ADME PGx panel simultaneously analyses 192 SNPs in 36 genes such as CYP1A, 2A6, 2B6, 2C19, $2 C 8 / 9,2 D 6,2 E 1,3 A 4 / 5$, phase II drug-metabolising enzymes and drug transporters. Analysis is provided by the MassARRAY system.

Targeted assay panels can be created using the Assay Explorer program [163].

The iPLEX ADME CYP2C9/VKORC1 panel is a set of 36 SNPs for $C Y P 2 C 9$ and 9 SNPs for VKORC1. The iPLEX ADME CYP2C19 panel analyses 31 SNPs for CYP2C19. 


\subsubsection{INFINITI $^{\circledR}$ CYP2C19 Assay}

The assay marketed by Autogenomics uses a hybridisation capture array with instrument-performed automated detection of multiple PCR products. PCR amplification is done offline while the rest of the processes are automated by the AutoGenomics INFINITI Analyzer. The assay is available in two formats: one sample per microarray chip or four samples. It identifies only the CYP $2 C 19 * 2, * 3$ and *17 alleles and corresponding genotype polymorphisms. The assay report lists the alleles and provides the genotype detected (wild type, mutant, heterozygote). The call rate reported by the manufacturer is greater than $90 \%$ with no incorrect call rate [164].

\subsection{5 eSensor $^{\circledR}$ Warfarin Sensitivity Test}

This DNA hybridisation and electrochemical detection test is marketed by GenMark and allows detection and genotyping of CYP450 2C9 (*2 and *3) and VKORC1 $(-1639 \mathrm{G}>\mathrm{A})$, with a result produced in approximately $3.5 \mathrm{~h}[165]$.

\subsubsection{Spartan RX CYP2C19 System}

This kit identifies carriers of the $C Y P 2 C 19 * 2$ allele using a cheek swab and adding sample to a cartridge then placing into a Spartan RX machine, printing a result in $1 \mathrm{~h} \mathrm{[166].}$

\subsection{Phenotyping}

Phenotyping consists of the administration of a "model" or probe drug metabolised by an individual specific CYP. The assessment of different PK parameters of the probe drug and its metabolites or the determination of a ratio between the drug and its metabolite (metabolic ratio, MR) allow the definition of an individual metabolic profile. When a genetic polymorphism is clearly defined for a specific CYP isoform, the phenotyping tests permit the distinction between individuals [167]. The individual phenotyping involves administration of one CYP-specific probe, whereas the simultaneous phenotyping involves concomitant administration of multiple specific probes (probes cocktail) and allows the concurrent detection of the activity of multiple enzymes [168]. A phenotyping cocktail made of a mixture of probes has some advantages because a simultaneous determination of several CYP activities in a single test is possible, avoiding the influence of variability over time on phenotyping results [169-173]. Several drugs have been documented as CYP2D6 phenotyping probes. Debrisoquine and sparteine have been frequently used, but concerns about their availability and safety have limited their use [174]. Recently, dextromethorphan has been considered as the probe of choice for CYP2D6 activity assessment by measuring the metabolic ratio $\mathrm{DEM} / \mathrm{DOR}_{\text {total }}$ in urine after $8 \mathrm{~h} \mathrm{[175-177].} \mathrm{Omeprazole} \mathrm{is} \mathrm{the} \mathrm{preferred}$ probe test for CYP2C19 phenotyping [178-180]. In all of the proposed cocktails caffeine was found to be the best probe drug for CYP1A2 phenotyping [181-183]. Several probes have been proposed for CYP3A activity assessment, including erythromycin, dapsone and endogenous cortisol. Midazolam is also a standard probe for this CYP owing to its selectivity and absence of transport by P-glycoprotein, which is also subject to high interindividual variability. However, oral administration of midazolam does not allow differentiation between CYP3A4 and CYP3A5 [184, 185]. Diverse probe drugs have been proposed to measure CYP2C9 enzymatic activity. These include mostly warfarin, tolbutamide, losartan and flurbiprofen [186]. For CYP2B6, the European Medicines Agency (EMA) recommend bupropion as a potential probe drug for CYP2B6 assessment [187]. One of the major drawbacks of phenotyping is the occurrence of side effects and PK-PD interactions between the probes when therapeutic doses of probes are used. The probability of such interactions and adverse effects may be minimised by the use of low dose probe drugs. Micrococktails using microdoses of each probe drug are therefore now being developed.

Another drawback of the phenotyping methods is the tedious sample collection. In fact, most validated cocktails need more than one blood sample and urine collection for at least $8 \mathrm{~h}$. Alternative sampling procedures are continuously developed and optimised in order to improve patients' comfort and reduce the quantity of collected fluid. Recently, a dried blood spot (DBS) sampling procedure was validated for the individual assessment of CYP2C9 activity using flurbiprofen as probe drug [188]. This procedure has the advantage of being less invasive, more costeffective and easier to transport and store in comparison to the standard venous blood sampling [189]. Owing to its non-invasiveness and the low volume required, the DBS procedure is perfectly adapted for the evaluation of the PK properties of a drug in clinical studies or for the evaluation of the enzymatic activity [190].

\section{Conclusion}

We have presented here the relevant data where genotyping and phenotyping may be considered, and the guidelines developed when available. Guidelines have been published for codeine and CYP2D6 [53], clopidogrel and CYP2C19 [92] and warfarin and CYP2C9 [130], as well as for some TCAs and SSRIs (Table 3).

Over the last decade, the knowledge of pharmacogenetic modulators has increased so that individualised pre-emptive 
therapy adjusted to the patient's genetic background could get closer to reality [191]. Furthermore, the American and European regulatory agencies (FDA and EMA) have recognised the clinical value of pharmacogenetics and have developed guidelines for industry concerning pharmacogenomic data submission with new drugs. They now recommend updating drug labels when compelling data are present [192]. Better therapeutic outcome has been associated with the choice of treatment and/or dose adjustment according to patient's genetic make-up in the field of oncology, cardiovascular medicine, psychiatrics and pain [193].

However, the use of pharmacogenetics has remained limited because of the paucity of studies showing that pharmacogenetic testing leads to improved clinical outcomes. So far, pharmacogenetics has been mainly used in a retrospective manner in order to identify and explain causes of abnormal responses (either inefficacy or toxicity) in individual patients.

Regarding drugs already on the market, pharmacogenetic-based dosing could be used if large prospective studies showed the benefit of pre-emptive genotyping associated with better outcomes, but these studies are so far very sparse.

A detailed knowledge of pharmacology is a prerequisite for application in clinical practice, and physicians might find it difficult to interpret the clinical value of pharmacogenetic test results. Guidelines that link the result of a pharmacogenetic test to therapeutic recommendations might help to overcome these problems. Slowly, peerreviewed drug-dosing guidelines based on individual genotypes are being published. These guidelines are updated periodically by PharmGKB, a comprehensive resource that curates knowledge about the impact of genetic variation on drug response for clinicians and researchers, from the accumulation of gene-drug knowledge to the implementation of pharmacogenomics in the clinic. These guidelines are available on the PharmGKB website [54].

In addition, new diagnostic techniques made safer and easier should allow quicker diagnosis of metabolic variations.

Therefore, though it may appear premature to recommend the application of a single genetic test before the start of the treatment; pharmacogenetics might already help to identify the right molecule for the right patient.

Acknowledgment and disclosures No sources of funding were used to prepare this review. The authors have no conflicts of interest that are directly relevant to the content of this review.

Open Access This article is distributed under the terms of the Creative Commons Attribution Noncommercial License which permits any noncommercial use, distribution, and reproduction in any medium, provided the original author(s) and the source are credited.

\section{References}

1. Franceschi M, et al. Prevalence, clinical features and avoidability of adverse drug reactions as cause of admission to a geriatric unit: a prospective study of 1756 patients. Drug Saf. 2008;31(6):545-56.

2. Lazarou J, Pomeranz BH, Corey PN. Incidence of adverse drug reactions in hospitalized patients: a meta-analysis of prospective studies. JAMA. 1998;279(15):1200-5.

3. Moore N, et al. Frequency and cost of serious adverse drug reactions in a department of general medicine. Br J Clin Pharmacol. 1998;45(3):301-8.

4. Einarson TR. Drug-related hospital admissions. Ann Pharmacother. 1993;27(7-8):832-40.

5. Wilkinson GR. Drug metabolism and variability among patients in drug response. N Engl J Med. 2005;352(21):2211-21.

6. Nelson DR. The cytochrome p450 homepage. Hum Genomics. 2009;4(1):59-65.

7. Evans WE, Relling MV. Pharmacogenomics: translating functional genomics into rational therapeutics. Science. 1999; 286(5439):487-91.

8. Eichelbaum M, Ingelman-Sundberg M, Evans WE. Pharmacogenomics and individualized drug therapy. Annu Rev Med. 2006;57:119-37.

9. Zanger UM, Raimundo S, Eichelbaum M. Cytochrome P450 2D6: overview and update on pharmacology, genetics, biochemistry. Naunyn Schmiedebergs Arch Pharmacol. 2004; 369(1):23-37.

10. http://www.cypalleles.ki.se/cyp2d6.htm. Accessed 19 Nov 2012.

11. Ingelman-Sundberg $\mathrm{M}$, et al. Influence of cytochrome P450 polymorphisms on drug therapies: pharmacogenetic, pharmacoepigenetic and clinical aspects. Pharmacol Ther. 2007; 116(3):496-526.

12. McGraw J, Waller D. Cytochrome P450 variations in different ethnic populations. Expert Opin Drug Metab Toxicol. 2012;8(3): 371-82.

13. http://www.ncbi.nlm.nih.gov/SNP/. Accessed 19 Nov 2012.

14. http://alfred.med.yale.edu/. Accessed 19 Nov 2012.

15. http://www.1000genomes.org/. Accessed 19 Nov 2012.

16. Bradford LD. CYP2D6 allele frequency in European Caucasians, Asians, Africans and their descendants. Pharmacogenomics. 2002;3(2):229-43.

17. Daly AK. Pharmacogenetics of the major polymorphic metabolizing enzymes. Fundam Clin Pharmacol. 2003;17(1):27-41.

18. Ingelman-Sundberg M, Oscarson M, McLellan RA. Polymorphic human cytochrome P450 enzymes: an opportunity for individualized drug treatment. Trends Pharmacol Sci. 1999;20(8):342-9.

19. Chen S, et al. The cytochrome P450 2D6 (CYP2D6) enzyme polymorphism: screening costs and influence on clinical outcomes in psychiatry. Clin Pharmacol Ther. 1996;60(5):522-34.

20. Chou WH, et al. Extension of a pilot study: impact from the cytochrome P450 2D6 polymorphism on outcome and costs associated with severe mental illness. J Clin Psychopharmacol. 2000;20(2):246-51.

21. Kirchheiner J, et al. Pharmacogenetics of antidepressants and antipsychotics: the contribution of allelic variations to the phenotype of drug response. Mol Psychiatry. 2004;9(5):442-73.

22. Cascorbi I. Pharmacogenetics of cytochrome p4502D6: genetic background and clinical implication. Eur $\mathbf{J}$ Clin Invest. 2003;33(Suppl 2):17-22.

23. Kawanishi C, et al. Increased incidence of CYP2D6 gene duplication in patients with persistent mood disorders: ultrarapid metabolism of antidepressants as a cause of nonresponse. A pilot study. Eur J Clin Pharmacol. 2004;59(11):803-7. 
24. Bertilsson L, et al. Molecular genetics of CYP2D6: clinical relevance with focus on psychotropic drugs. Br J Clin Pharmacol. 2002;53(2):111-22.

25. Spina E, et al. Relationship between plasma desipramine levels, CYP2D6 phenotype and clinical response to desipramine: a prospective study. Eur J Clin Pharmacol. 1997;51(5):395-8.

26. Steimer W, et al. Amitriptyline or not, that is the question: pharmacogenetic testing of CYP2D6 and CYP2C19 identifies patients with low or high risk for side effects in amitriptyline therapy. Clin Chem. 2005;51(2):376-85.

27. Kirchheiner J, et al. CYP2D6 and CYP2C19 genotype-based dose recommendations for antidepressants: a first step towards subpopulation-specific dosages. Acta Psychiatr Scand. 2001; 104(3):173-92.

28. Swen JJ, et al. Pharmacogenetics: from bench to byte-an update of guidelines. Clin Pharmacol Ther. 2011;89(5):662-73.

29. Dahl ML. Cytochrome p450 phenotyping/genotyping in patients receiving antipsychotics: useful aid to prescribing? Clin Pharmacokinet. 2002;41(7):453-70.

30. Schillevoort I, et al. Antipsychotic-induced extrapyramidal syndromes and cytochrome P450 2D6 genotype: a case-control study. Pharmacogenetics. 2002;12(3):235-40.

31. Brockmoller J, et al. The impact of the CYP2D6 polymorphism on haloperidol pharmacokinetics and on the outcome of haloperidol treatment. Clin Pharmacol Ther. 2002;72(4):438-52.

32. Tamminga WJ, et al. Polymorphic drug metabolism (CYP2D6) and utilisation of psychotropic drugs in hospitalised psychiatric patients: a retrospective study. Eur J Clin Pharmacol. 2003;59(1):57-64.

33. Patsopoulos NA, et al. CYP2D6 polymorphisms and the risk of tardive dyskinesia in schizophrenia: a meta-analysis. Pharmacogenet Genomics. 2005;15(3):151-8.

34. Desmeules J, et al. Impact of environmental and genetic factors on codeine analgesia. Eur J Clin Pharmacol. 1991;41(1):23-6.

35. Caraco Y, Sheller J, Wood AJ. Pharmacogenetic determination of the effects of codeine and prediction of drug interactions. J Pharmacol Exp Ther. 1996;278(3):1165-74.

36. Poulsen L, et al. The hypoalgesic effect of tramadol in relation to CYP2D6. Clin Pharmacol Ther. 1996;60(6):636-44.

37. Samer CF, et al. The effects of CYP2D6 and CYP3A activities on the pharmacokinetics of immediate release oxycodone. $\mathrm{Br} \mathrm{J}$ Pharmacol. 2010;160(4):907-18.

38. Samer CF, et al. Genetic polymorphisms and drug interactions modulating CYP2D6 and CYP3A activities have a major effect on oxycodone analgesic efficacy and safety. Br J Pharmacol. 2010;160(4):919-30.

39. Brousseau DC, et al. The effect of CYP2D6 polymorphisms on the response to pain treatment for pediatric sickle cell pain crisis. J Pediatr. 2007;150(6):623-6.

40. Stamer UM, et al. Impact of CYP2D6 genotype on postoperative tramadol analgesia. Pain. 2003;105(1-2):231-8.

41. Kirchheiner J, et al. Effects of the CYP2D6 gene duplication on the pharmacokinetics and pharmacodynamics of tramadol. J Clin Psychopharmacol. 2008;28(1):78-83.

42. Dalen $P$, et al. Quick onset of severe abdominal pain after codeine in an ultrarapid metabolizer of debrisoquine. Ther Drug Monit. 1997;19(5):543-4.

43. de Leon J, Dinsmore L, Wedlund P. Adverse drug reactions to oxycodone and hydrocodone in CYP2D6 ultrarapid metabolizers. J Clin Psychopharmacol. 2003;23(4):420-1.

44. Madadi $\mathrm{P}$, et al. Pharmacogenetics of neonatal opioid toxicity following maternal use of codeine during breastfeeding: a casecontrol study. Clin Pharmacol Ther. 2009;85(1):31-5.

45. Koren G, et al. Pharmacogenetics of morphine poisoning in a breastfed neonate of a codeine-prescribed mother. Lancet. 2006;368(9536):704.
46. Stamer UM, Zhang L, Stuber F. Personalized therapy in pain management: where do we stand? Pharmacogenomics. 2010; 11(6):843-64

47. Voronov P, Przybylo HJ, Jagannathan N. Apnea in a child after oral codeine: a genetic variant-an ultra-rapid metabolizer. Paediatr Anaesth. 2007;17(7):684-7.

48. Madadi P, et al. Safety of codeine during breastfeeding: fatal morphine poisoning in the breastfed neonate of a mother prescribed codeine. Can Fam Physician. 2007;53(1):33-5.

49. Kelly LE, et al. More codeine fatalities after tonsillectomy in North American children. Pediatrics. 2012;129(5):e1343-7.

50. http://www.fda.gov/NewsEvents/Newsroom/PressAnnouncements/ 2007/ucm108968.htm. Accessed 19 Nov 2012.

51. http://www.fda.gov/Drugs/DrugSafety/ucm313631.htm. Accessed 19 Nov 2012.

52. http://www.fda.gov/Drugs/DrugSafety/ucm339112.htm. Accessed 19 Nov 2012.

53. Crews KR, et al. Clinical Pharmacogenetics Implementation Consortium (CPIC) guidelines for codeine therapy in the context of cytochrome P450 2D6 (CYP2D6) genotype. Clin Pharmacol Ther. 2012;91(2):321-6.

54. http://www.pharmgkb.org/. Accessed 19 Nov 2012.

55. Gasche $\mathrm{Y}$, et al. Codeine intoxication associated with ultrarapid CYP2D6 metabolism. New Engl J Med. 2004;351(27): 2827-31.

56. Collart L, et al. Duality of the analgesic effect of tramadol in humans. Schweiz Med Wochenschr. 1993;123(47):2241-3.

57. Overholser BR, Foster DR. Opioid pharmacokinetic drug-drug interactions. Am J Manag Care. 2011;17(Suppl 11):S276-87.

58. Rogers JF, Nafziger AN, Bertino JS Jr. Pharmacogenetics affects dosing, efficacy, and toxicity of cytochrome P450metabolized drugs. Am J Med. 2002;113(9):746-50.

59. Wuttke $\mathrm{H}$, et al. Increased frequency of cytochrome P450 2D6 poor metabolizers among patients with metoprolol-associated adverse effects. Clin Pharmacol Ther. 2002;72(4):429-37.

60. Lennard MS, et al. Debrisoquine polymorphism and the metabolism and action of metoprolol, timolol, propranolol and atenolol. Xenobiotica. 1986;16(5):435-47.

61. Giessmann T, et al. CYP2D6 genotype and induction of intestinal drug transporters by rifampin predict presystemic clearance of carvedilol in healthy subjects. Clin Pharmacol Ther. 2004;75(3):213-22.

62. Siddoway LA, et al. Polymorphism of propafenone metabolism and disposition in man: clinical and pharmacokinetic consequences. Circulation. 1987;75(4):785-91.

63. Graff DW, et al. Effect of fluoxetine on carvedilol pharmacokinetics, CYP2D6 activity, and autonomic balance in heart failure patients. J Clin Pharmacol. 2001;41(1):97-106.

64. Parker RB, Soberman JE. Effects of paroxetine on the pharmacokinetics and pharmacodynamics of immediate-release and extended-release metoprolol. Pharmacotherapy. 2011; 31(7):630-41.

65. Goryachkina K, et al. CYP2D6 is a major determinant of metoprolol disposition and effects in hospitalized Russian patients treated for acute myocardial infarction. Eur J Clin Pharmacol. 2008;64(12):1163-73.

66. Johnson MD, et al. Pharmacological characterization of 4-hydroxy-N-desmethyl tamoxifen, a novel active metabolite of tamoxifen. Breast Cancer Res Treat. 2004;85(2):151-9.

67. Mugundu GM, et al. Assessment of the impact of CYP3A polymorphisms on the formation of alpha-hydroxytamoxifen and $N$-desmethyltamoxifen in human liver microsomes. Drug Metab Dispos. 2012;40(2):389-96.

68. Jin Y, et al. CYP2D6 genotype, antidepressant use, and tamoxifen metabolism during adjuvant breast cancer treatment. J Natl Cancer Inst. 2005;97(1):30-9. 
69. Stearns V, et al. Active tamoxifen metabolite plasma concentrations after coadministration of tamoxifen and the selective serotonin reuptake inhibitor paroxetine. J Natl Cancer Inst. 2003;95(23):1758-64.

70. Murdter TE, et al. Activity levels of tamoxifen metabolites at the estrogen receptor and the impact of genetic polymorphisms of phase I and II enzymes on their concentration levels in plasma. Clin Pharmacol Ther. 2011;89(5):708-17.

71. Rolla R, et al. Side effects associated with ultrarapid cytochrome P450 2D6 genotype among women with early stage breast cancer treated with tamoxifen. Clin Lab. 2012;58(11-12): 1211-8.

72. Schroth $\mathrm{W}$, et al. Breast cancer treatment outcome with adjuvant tamoxifen relative to patient CYP2D6 and CYP2C19 genotypes. J Clin Oncol. 2007;25(33):5187-93.

73. Schroth W, et al. Association between CYP2D6 polymorphisms and outcomes among women with early stage breast cancer treated with tamoxifen. JAMA. 2009;302(13):1429-36.

74. Bijl MJ, et al. The CYP2D6*4 polymorphism affects breast cancer survival in tamoxifen users. Breast Cancer Res Treat. 2009;118(1):125-30.

75. Lim HS, et al. Clinical implications of CYP2D6 genotypes predictive of tamoxifen pharmacokinetics in metastatic breast cancer. J Clin Oncol. 2007;25(25):3837-45.

76. Lim JS, et al. Impact of CYP2D6, CYP3A5, CYP2C9 and CYP2C19 polymorphisms on tamoxifen pharmacokinetics in Asian breast cancer patients. Br J Clin Pharmacol. 2011;71(5): 737-50.

77. Kiyotani K, et al. Impact of CYP2D6*10 on recurrence-free survival in breast cancer patients receiving adjuvant tamoxifen therapy. Cancer Sci. 2008;99(5):995-9.

78. Xu Y, et al. Association between CYP2D6 $* 10$ genotype and survival of breast cancer patients receiving tamoxifen treatment. Ann Oncol. 2008;19(8):1423-9.

79. Goetz MP, et al. CYP2D6 metabolism and patient uutcome in the Austrian Breast and Colorectal Cancer Study Group Trial (ABCSG) 8. Clin Cancer Res. 2013;19(2):500-7.

80. Kiyotani K, et al. Dose-adjustment study of tamoxifen based on CYP2D6 genotypes in Japanese breast cancer patients. Breast Cancer Res Treat. 2012;131(1):137-45.

81. Irvin WJ Jr, et al. Genotype-guided tamoxifen dosing increases active metabolite exposure in women with reduced CYP2D6 metabolism: a multicenter study. J Clin Oncol. 2011;29(24):3232-9.

82. Barginear MF, et al. Increasing tamoxifen dose in breast cancer patients based on CYP2D6 genotypes and endoxifen levels: effect on active metabolite isomers and the antiestrogenic activity score. Clin Pharmacol Ther. 2011;90(4):605-11.

83. Brauch H, et al. Tamoxifen use in postmenopausal breast cancer: CYP2D6 matters. J Clin Oncol. 2013;31:176-80.

84. Binkhorst L, van Gelder T, Mathijssen RH. Individualization of tamoxifen treatment for breast carcinoma. Clin Pharmacol Ther. 2012;92(4):431-3.

85. Regan MM, et al. CYP2D6 genotype and tamoxifen response in postmenopausal women with endocrine-responsive breast cancer: The Breast International Group 1-98 trial. J Natl Cancer Inst. 2012;104(6):441-51.

86. Rae JM, et al. CYP2D6 and UGT2B7 genotype and risk of recurrence in tamoxifen-treated breast cancer patients. J Natl Cancer Inst. 2012;104(6):452-60.

87. Nakamura Y, et al. Re: CYP2D6 genotype and tamoxifen response in postmenopausal women with endocrine-responsive breast cancer: the Breast International Group 1-98 trial. J Natl Cancer Inst. 2012;104(16):1264 (author reply 1266-8).

88. Zhou SF, Liu JP, Chowbay B. Polymorphism of human cytochrome P450 enzymes and its clinical impact. Drug Metab Rev. 2009;41(2):89-295.
89. Ingelman-Sundberg M. et al. The human cytochrome P450 (CYP) allele nomenclature database. CYP2C19 allele nomenclature. 2011. Available from http://www.cypalleles.ki.se/cyp2c19.htm.

90. Desta Z, et al. Clinical significance of the cytochrome P450 2C19 genetic polymorphism. Clin Pharmacokinet. 2002;41(12): 913-58.

91. Strom CM, et al. Testing for variants in CYP2C19: population frequencies and testing experience in a clinical laboratory. Genet Med. 2012;14(1):95-100.

92. Scott SA, et al. Clinical Pharmacogenetics Implementation Consortium guidelines for cytochrome P450-2C19 (CYP2C19) genotype and clopidogrel therapy. Clin Pharmacol Ther. 2011;90(2):328-32.

93. Martis S. et al. Multi-ethnic distribution of clinically relevant CYP2C genotypes and haplotypes. Pharmacogenomics J. 2012. doi:10.1038/tpj.2012.10. http://www.nature.com/tpj/journal/vaop/ ncurrent/abs/tpj201210a.html.

94. Floyd CN, Passacquale G, Ferro A. Comparative pharmacokinetics and pharmacodynamics of platelet adenosine diphosphate receptor antagonists and their clinical implications. Clin Pharmacokinet. 2012;51(7):429-42.

95. FDA. FDA drug safety communication: reduced effectiveness of Plavix (clopidogrel) in patients who are poor metabolizers of the drug. 2010. Available from: http://www.fda.gov/Drugs/Drug Safety/PostmarketDrugSafetyInformationforPatientsandProvide rs/ucm203888.htm.

96. Bauer T, et al. Impact of CYP2C19 variant genotypes on clinical efficacy of antiplatelet treatment with clopidogrel: systematic review and meta-analysis. BMJ. 2011;343:d4588.

97. Jang JS, et al. Meta-analysis of cytochrome P450 2C19 polymorphism and risk of adverse clinical outcomes among coronary artery disease patients of different ethnic groups treated with clopidogrel. Am J Cardiol. 2012;110(4):502-8.

98. Johnson JA, et al. Clopidogrel: a case for indication-specific pharmacogenetics. Clin Pharmacol Ther. 2012;91(5):774-6.

99. Sim SC, Kacevska M, Ingelman-Sundberg M. Pharmacogenomics of drug-metabolizing enzymes: a recent update on clinical implications and endogenous effects. Pharmacogenomics J. 2013;13:1-11.

100. Fock KM, et al. Proton pump inhibitors: do differences in pharmacokinetics translate into differences in clinical outcomes? Clin Pharmacokinet. 2008;47(1):1-6.

101. Ogawa R, Echizen H. Drug-drug interaction profiles of proton pump inhibitors. Clin Pharmacokinet. 2010;49(8):509-33.

102. Hagymasi K, et al. Update on the pharmacogenomics of proton pump inhibitors. Pharmacogenomics. 2011;12(6):873-88.

103. Shi S, Klotz U. Proton pump inhibitors: an update of their clinical use and pharmacokinetics. Eur J Clin Pharmacol. 2008;64(10):935-51.

104. Scott SA, et al. PharmGKB summary: very important pharmacogene information for cytochrome P450, family 2 , subfamily $\mathrm{C}$, polypeptide 19. Pharmacogenet Genomics. 2012;22(2):159-65.

105. Lorenzini KI, et al. Serotonin syndrome following drug-drug interactions and CYP2D6 and CYP2C19 genetic polymorphisms in an HIV-infected patient. AIDS. 2012;26(18):2417-8.

106. Rao N. The clinical pharmacokinetics of escitalopram. Clin Pharmacokinet. 2007;46(4):281-90.

107. Mrazek DA, et al. CYP2C19 variation and citalopram response. Pharmacogenet Genomics. 2011;21(1):1-9.

108. http://www.cypalleles.ki.se/cyp2c9.htm. Accessed 16 Nov 2012.

109. Rettie AE, et al. Impaired (S)-warfarin metabolism catalysed by the R144C allelic variant of CYP2C9. Pharmacogenetics. 1994;4(1):39-42.

110. Sullivan-Klose TH, et al. The role of the CYP2C9-Leu359 allelic variant in the tolbutamide polymorphism. Pharmacogenetics. 1996;6(4):341-9. 
111. Kirchheiner J, Brockmoller J. Clinical consequences of cytochrome P450 2C9 polymorphisms. Clin Pharmacol Ther. 2005;77(1):1-16.

112. Lee CR, Goldstein JA, Pieper JA. Cytochrome P450 2C9 polymorphisms: a comprehensive review of the in-vitro and human data. Pharmacogenetics. 2002;12(3):251-63.

113. Xie HG, et al. CYP2C9 allelic variants: ethnic distribution and functional significance. Adv Drug Deliv Rev. 2002;54(10): 1257-70.

114. Aithal GP, et al. Association of polymorphisms in the cytochrome P450 CYP2C9 with warfarin dose requirement and risk of bleeding complications. Lancet. 1999;353(9154):717-9.

115. Beyth RJ, Quinn L, Landefeld CS. A multicomponent intervention to prevent major bleeding complications in older patients receiving warfarin. A randomized, controlled trial. Ann Intern Med. 2000;133(9):687-95.

116. Sanderson S, Emery J, Higgins J. CYP2C9 gene variants, drug dose, and bleeding risk in warfarin-treated patients: a HuGEnet systematic review and meta-analysis. Genet Med. 2005;7(2): 97-104.

117. Higashi MK, et al. Association between CYP2C9 genetic variants and anticoagulation-related outcomes during warfarin therapy. JAMA. 2002;287(13):1690-8.

118. Joffe HV, et al. Warfarin dosing and cytochrome P450 2C9 polymorphisms. Thromb Haemost. 2004;91(6):1123-8.

119. Margaglione $\mathrm{M}$, et al. Genetic modulation of oral anticoagulation with warfarin. Thromb Haemost. 2000;84(5):775-8.

120. Peyvandi F, et al. CYP2C9 genotypes and dose requirements during the induction phase of oral anticoagulant therapy. Clin Pharmacol Ther. 2004;75(3):198-203.

121. Tassies D, et al. Pharmacogenetics of acenocoumarol: cytochrome P450 CYP2C9 polymorphisms influence dose requirements and stability of anticoagulation. Haematologica. 2002;87(11):1185-91.

122. Schalekamp T, et al. Acenocoumarol stabilization is delayed in CYP2C93 carriers. Clin Pharmacol Ther. 2004;75(5):394-402.

123. Taube J, Halsall D, Baglin T. Influence of cytochrome P-450 CYP2C9 polymorphisms on warfarin sensitivity and risk of over-anticoagulation in patients on long-term treatment. Blood. 2000;96(5):1816-9.

124. Verhoef TI, et al. Long-term anticoagulant effects of the CYP2C9 and VKORC1 genotypes in acenocoumarol users. J Thromb Haemost. 2012;10(4):606-14.

125. Lindh JD, et al. Several-fold increase in risk of overanticoagulation by CYP2C9 mutations. Clin Pharmacol Ther. 2005;78(5): 540-50.

126. Hermida J, et al. Differential effects of $2 \mathrm{C} 9 * 3$ and $2 \mathrm{C} 9 * 2$ variants of cytochrome P-450 CYP2C9 on sensitivity to acenocoumarol. Blood. 2002;99(11):4237-9.

127. Thijssen HH, Ritzen B. Acenocoumarol pharmacokinetics in relation to cytochrome P450 2C9 genotype. Clin Pharmacol Ther. 2003;74(1):61-8.

128. Spreafico M, et al. Effects of CYP2C9 and VKORC1 on INR variations and dose requirements during initial phase of anticoagulant therapy. Pharmacogenomics. 2008;9(9):1237-50.

129. Visser LE, et al. The risk of overanticoagulation in patients with heart failure on coumarin anticoagulants. $\mathrm{Br} \mathrm{J}$ Haematol. 2004;127(1):85-9.

130. Johnson JA, et al. Clinical Pharmacogenetics Implementation Consortium Guidelines for CYP2C9 and VKORC1 genotypes and warfarin dosing. Clin Pharmacol Ther. 2011;90(4):625-9.

131. http://www.warfarindosing.org/. Accessed 19 Nov 2012.

132. Leemann TD, et al. A major role for cytochrome P450TB (CYP2C subfamily) in the actions of non-steroidal antiinflammatory drugs. Drugs Exp Clin Res. 1993;19(5):189-95.
133. Martinez C, et al. Genetic predisposition to acute gastrointestinal bleeding after NSAIDs use. Br J Pharmacol. 2004;141(2): 205-8.

134. Pilotto A, et al. Genetic susceptibility to nonsteroidal antiinflammatory drug-related gastroduodenal bleeding: role of cytochrome P450 2C9 polymorphisms. Gastroenterology. 2007;133(2):465-71.

135. Carbonell N, et al. CYP2C9*3 loss-of-function allele is associated with acute upper gastrointestinal bleeding related to the use of NSAIDs other than aspirin. Clin Pharmacol Ther. 2010;87(6):693-8.

136. Martin $\mathrm{JH}$, et al. Is cytochrome $\mathrm{P} 4502 \mathrm{C} 9$ genotype associated with NSAID gastric ulceration? $\mathrm{Br} \mathrm{J}$ Clin Pharmacol. 2001;51(6):627-30.

137. Vonkeman HE, et al. Allele variants of the cytochrome P450 2C9 genotype in white subjects from the Netherlands with serious gastroduodenal ulcers attributable to the use of NSAIDs. Clin Ther. 2006;28(10):1670-6.

138. Holstein A, et al. Association between CYP2C9 slow metabolizer genotypes and severe hypoglycaemia on medication with sulphonylurea hypoglycaemic agents. $\mathrm{Br} \mathrm{J}$ Clin Pharmacol. 2005;60(1):103-6.

139. Elliot DJ, et al. Identification of the human cytochromes P450 catalysing the rate-limiting pathways of gliclazide elimination. Br J Clin Pharmacol. 2007;64(4):450-7.

140. Naritomi Y, Terashita S, Kagayama A. Identification and relative contributions of human cytochrome $\mathrm{P} 450$ isoforms involved in the metabolism of glibenclamide and lansoprazole: evaluation of an approach based on the in vitro substrate disappearance rate. Xenobiotica. 2004;34(5):415-27.

141. Kirchheiner J, et al. Impact of CYP2C9 and CYP2C19 polymorphisms on tolbutamide kinetics and the insulin and glucose response in healthy volunteers. Pharmacogenetics. 2002;12(2):101-9.

142. Kirchheiner J, et al. Impact of CYP2C9 amino acid polymorphisms on glyburide kinetics and on the insulin and glucose response in healthy volunteers. Clin Pharmacol Ther. 2002;71(4):286-96.

143. Niemi M, et al. Glyburide and glimepiride pharmacokinetics in subjects with different CYP2C9 genotypes. Clin Pharmacol Ther. 2002;72(3):326-32.

144. Gokalp O, et al. Mild hypoglycaemic attacks induced by sulphonylureas related to CYP2C9, CYP2C19 and CYP2C8 polymorphisms in routine clinical setting. Eur J Clin Pharmacol. 2011;67(12):1223-9.

145. Yasar U, et al. Role of CYP2C9 polymorphism in losartan oxidation. Drug Metab Dispos. 2001;29(7):1051-6.

146. Lo MW, et al. Pharmacokinetics of losartan, an angiotensin II receptor antagonist, and its active metabolite EXP3174 in humans. Clin Pharmacol Ther. 1995;58(6):641-9.

147. Yasar U, et al. Pharmacokinetics of losartan and its metabolite E-3174 in relation to the CYP2C9 genotype. Clin Pharmacol Ther. 2002;71(1):89-98.

148. Lajer M, et al. CYP2C9 variant modifies blood pressure-lowering response to losartan in type 1 diabetic patients with nephropathy. Diabet Med. 2007;24(3):323-5.

149. Hong X, et al. CYP2C9*3 allelic variant is associated with metabolism of irbesartan in Chinese population. Eur J Clin Pharmacol. 2005;61(9):627-34.

150. Hallberg P, et al. The CYP2C9 genotype predicts the blood pressure response to irbesartan: results from the Swedish Irbesartan Left Ventricular Hypertrophy Investigation vs Atenolol (SILVHIA) trial. J Hypertens. 2002;20(10):2089-93.

151. van der Weide $\mathrm{J}$, et al. The effect of genetic polymorphism of cytochrome P450 CYP2C9 on phenytoin dose requirement. Pharmacogenetics. 2001;11(4):287-91. 
152. Aynacioglu AS, et al. Frequency of cytochrome P450 CYP2C9 variants in a Turkish population and functional relevance for phenytoin. Br J Clin Pharmacol. 1999;48(3):409-15.

153. Mamiya K, et al. The effects of genetic polymorphisms of CYP2C9 and CYP2C19 on phenytoin metabolism in Japanese adult patients with epilepsy: studies in stereoselective hydroxylation and population pharmacokinetics. Epilepsia. 1998; 39(12):1317-23.

154. Hung CC, et al. Dosage recommendation of phenytoin for patients with epilepsy with different CYP2C9/CYP2C19 polymorphisms. Ther Drug Monit. 2004;26(5):534-40.

155. Lee AY, et al. Genetic polymorphism of cytochrome P450 2C9 in diphenylhydantoin-induced cutaneous adverse drug reactions. Eur J Clin Pharmacol. 2004;60(3):155-9.

156. Kesavan R, Narayan SK, Adithan C. Influence of CYP2C9 and CYP2C19 genetic polymorphisms on phenytoin-induced neurological toxicity in Indian epileptic patients. Eur J Clin Pharmacol. 2010;66(7):689-96.

157. Kivisto KT, Kroemer HK. Use of probe drugs as predictors of drug metabolism in humans. J Clin Pharmacol. 1997;37(1 Suppl):40S-8S.

158. de Leon J. AmpliChip CYP450 test: personalized medicine has arrived in psychiatry. Expert Rev Mol Diagn. 2006;6(3):277-86.

159. Heller T, et al. AmpliChip CYP450 GeneChip: a new gene chip that allows rapid and accurate CYP2D6 genotyping. Ther Drug Monit. 2006;28(5):673-7.

160. de Leon J, Arranz MJ, Ruano G. Pharmacogenetic testing in psychiatry: a review of features and clinical realities. Clin Lab Med. 2008;28(4):599-617.

161. de Leon J, Susce MT, Murray-Carmichael E. The AmpliChip CYP450 genotyping test: integrating a new clinical tool. Mol Diagn Ther. 2006;10(3):135-51.

162. Rebsamen MC, et al. The AmpliChip CYP450 test: cytochrome P450 2D6 genotype assessment and phenotype prediction. Pharmacogenomics J. 2009;9(1):34-41.

163. http://www.sequenom.com/ADME-PGx-Genotyping. Accessed 19 Nov 2012.

164. http://www.autogenomics.com/pdf/EM-34036-C-INFINITI-CY P2C19-Package-Insert.pdf. Accessed 19 Nov 2012.

165. http://www.genmarkdx.com/technology/index.php. Accessed 19 Nov 2012.

166. http://www.spartanbio.com/products/spartan-rx/. Accessed 19 Nov 2012.

167. Streetman DS, Bertino JS Jr, Nafziger AN. Phenotyping of drugmetabolizing enzymes in adults: a review of in-vivo cytochrome P450 phenotyping probes. Pharmacogenetics. 2000;10(3):187-216.

168. Jerdi MC, et al. A simplified analytical method for a phenotyping cocktail of major CYP450 biotransformation routes. J Pharm Biomed Anal. 2004;35(5):1203-12.

169. Breimer DD, Schellens JH. A 'cocktail' strategy to assess in vivo oxidative drug metabolism in humans. Trends Pharmacol Sci. 1990;11(6):223-5.

170. Frye RF, et al. Validation of the five-drug "Pittsburgh cocktail" approach for assessment of selective regulation of drug-metabolizing enzymes. Clin Pharmacol Ther. 1997;62(4):365-76.

171. Zhu B, et al. Assessment of cytochrome P450 activity by a fivedrug cocktail approach. Clin Pharmacol Ther. 2001;70(5): 455-61.

172. Chainuvati S, et al. Combined phenotypic assessment of cytochrome p450 1A2, 2C9, 2C19, 2D6, and 3A, N-acetyltransferase-2, and xanthine oxidase activities with the "Cooperstown $5+1$ cocktail". Clin Pharmacol Ther. 2003;74(5):437-47.

173. Streetman DS, et al. Combined phenotypic assessment of CYP1A2, CYP2C19, CYP2D6, CYP3A, N-acetyltransferase-2, and xanthine oxidase with the "Cooperstown cocktail". Clin Pharmacol Ther. 2000;68(4):375-83.

174. Tanaka E, Kurata N, Yasuhara H. How useful is the "cocktail approach" for evaluating human hepatic drug metabolizing capacity using cytochrome $\mathrm{P} 450$ phenotyping probes in vivo? J Clin Pharm Ther. 2003;28(3):157-65.

175. Schmid B, et al. Polymorphic dextromethorphan metabolism: co-segregation of oxidative $O$-demethylation with debrisoquin hydroxylation. Clin Pharmacol Ther. 1985;38(6):618-24.

176. Capon DA, et al. The influence of CYP2D6 polymorphism and quinidine on the disposition and antitussive effect of dextromethorphan in humans. Clin Pharmacol Ther. 1996;60(3):295-307.

177. Sachse C, et al. Cytochrome P450 2D6 variants in a Caucasian population: allele frequencies and phenotypic consequences. Am J Hum Genet. 1997;60(2):284-95.

178. Balian JD, et al. The hydroxylation of omeprazole correlates with S-mephenytoin metabolism: a population study. Clin Pharmacol Ther. 1995;57(6):662-9.

179. Tybring G, et al. Enantioselective hydroxylation of omeprazole catalyzed by CYP2C19 in Swedish white subjects. Clin Pharmacol Ther. 1997;62(2):129-37.

180. Chang M, et al. Interphenotype differences in disposition and effect on gastrin levels of omeprazole-suitability of omeprazole as a probe for CYP2C19. Br J Clin Pharmacol. 1995;39(5): 511-8.

181. Ou-Yang DS, et al. Phenotypic polymorphism and genderrelated differences of CYP1A2 activity in a Chinese population. Br J Clin Pharmacol. 2000;49(2):145-51.

182. Sachse C, et al. Functional significance of a $\mathrm{C}->$ A polymorphism in intron 1 of the cytochrome P450 CYP1A2 gene tested with caffeine. Br J Clin Pharmacol. 1999;47(4):445-9.

183. Spigset $\mathrm{O}$, et al. The paraxanthine:caffeine ratio in serum or in saliva as a measure of CYP1A2 activity: when should the sample be obtained? Pharmacogenetics. 1999;9(3):409-12.

184. Lin YS, et al. In-vivo phenotyping for CYP3A by a single-point determination of midazolam plasma concentration. Pharmacogenetics. 2001;11(9):781-91.

185. Wandel C, et al. Relationship between hepatic cytochrome P450 $3 \mathrm{~A}$ content and activity and the disposition of midazolam administered orally. Drug Metab Dispos. 1998;26(2):110-4.

186. Meadowcroft AM, et al. The effects of fluvastatin, a CYP2C9 inhibitor, on losartan pharmacokinetics in healthy volunteers. J Clin Pharmacol. 1999;39(4):418-24.

187. EMEA. Guideline on the investigation of drug interactions. 2010. Available from: http://www.emea.europa.eu/docs/en_GB/ document_library/Scientific_guideline/2010/05/WC500090112.pdf.

188. Daali $\mathrm{Y}$, et al. Oral flurbiprofen metabolic ratio assessment using a single-point dried blood spot. Clin Pharmacol Ther. 2012;91(3):489-96.

189. Deglon J, et al. Direct analysis of dried blood spots coupled with mass spectrometry: concepts and biomedical applications. Anal Bioanal Chem. 2012;402(8):2485-98.

190. Spooner N, Lad R, Barfield M. Dried blood spots as a sample collection technique for the determination of pharmacokinetics in clinical studies: considerations for the validation of a quantitative bioanalytical method. Anal Chem. 2009;81(4):1557-63.

191. Rollason V, et al. Pharmacogenetics of analgesics: toward the individualization of prescription. Pharmacogenomics. 2008; 9(7):905-33.

192. Singh D, et al. Novel advances in cytochrome P450 research. Drug Discov Today. 2011;16(17-18):793-9.

193. Freedman AN, et al. Cancer pharmacogenomics and pharmacoepidemiology: setting a research agenda to accelerate translation. J Natl Cancer Inst. 2010;102(22):1698-705. 